\title{
Why Do Sellers (Usually) Prefer Auctions?
}

\author{
Jeremy Bulow and Paul Klemperer* \\ forthcoming American Economic Review, 2009
}

\begin{abstract}
We compare the most common methods for selling a company or other asset when participation is costly: a simple simultaneous auction, and a sequential process in which potential buyers decide in turn whether or not to enter the bidding. The sequential process is always more efficient. But pre-emptive bids transfer surplus from the seller to buyers. Because the auction is more conducive to entry - precisely because of its inefficiency - it usually generates higher expected revenue. We also discuss the effects of lock-ups, matching rights, break-up fees (as in takeover battles), entry subsidies, etc.
\end{abstract}

JELs: D44 Auctions; G34 Mergers \& Acquisitions; L13 Oligopoly \& Imperfect Markets. Keywords: Auctions, jump bidding, sequential sales, procurement, entry

Why do sellers like auctions? The simple answer is that auctions involve bidders competing simultaneously, and this benefits sellers.

But when entry is costly, auctions are inefficient. Sequential mechanisms are more efficient, because later potential bidders can use the information from early bids in deciding whether to undertake costly search and entry. If a seller can capture enough of the efficiency gain from sequential entry, it is more profitable for it to deal with just one bidder at a time, letting the bidders respond to the potential competition from potential buyers, with the

\footnotetext{
*Bulow: Graduate School of Business, Stanford University, Stanford CA 94305-5015, jbulow@stanford.edu. Klemperer: Nuffield College, University of Oxford, Oxford OX1 1NF United Kingdom, paul.klemperer@economics.ox.ac.uk. We owe thanks to many colleagues including Elizabeth Baldwin, Eric Budish, Vince Crawford, Michael Grubb, Ian Jewitt, Daniel Marszalec, Meg Meyer, Marco Pagnozzi, Ivan Png, Eric Rasmusen, Robert Ritz, Yuval Salant, Ron Siegel, Bruno Strulovici, and our referees for their careful readings of the paper and their many valuable comments. We also thank Robert Jeffe (Managing Director and Chairman, Corporate Advisory Group, Deutsche Bank Securities), and members of the Oxford and Stanford Executive MBA programmes, for educating us about the mechanics of corporate transactions.
} 
entry costs for actual competition being incurred only when the early bidders turn out to have low values. ${ }^{1}$

Nevertheless, any additional rents created by real-world sequential mechanisms - and more - seemingly accrue to buyers: although some sellers of businesses, especially in the "middle market", purposely choose to negotiate sequentially with one buyer at a time, ${ }^{2}$ about 80 percent of private equity firms in a recent poll said they prefer to use auctions when acting as sellers. Meanwhile about 90 percent of the same firms said they preferred to avoid auctions when acting as buyers. ${ }^{3}$ Warren Buffet famously states each year in his annual report under "Acquisition Criteria": "[W] don't want to waste our time ...We don't participate in auctions" (italics in original), and Bruce Wasserstein (2001), the most successful U.S. mergers and acquisitions banker of the past 30 years, writes "A wide-ranging auction generally maximizes value... sophisticated bidders will do their best to circumvent the auction format."

This paper therefore focuses on comparing the two dominant methods for selling public companies - a simple "plain vanilla" simultaneous auction and an equally simple model of a sequential sales mechanism - when the seller has realistically-limited power and information. ${ }^{4}$ (Similar alternative ways of selling are observed for many other assets. ${ }^{5}$ )

In both processes we model, an unknown number of potential bidders make entry decisions sequentially, before learning their values. In an auction, no credible bidding is possible until all entry decisions have been taken. In a sequential mechanism, potential bidders arrive in turn. Each one observes the current price and bidding history and decides whether to pay the entry cost to learn its value. If it does, and if it succeeds in outbidding any current incumbent (who can respond by raising its own bid), it can also make any additional "jump bid" it wishes to attempt to deter further entry. In both processes, we assume the seller does not have the power or credibility to commit to a take-it-or-leave-it minimum (reservation)

\footnotetext{
${ }^{1}$ Nihat Aktas, Eric de Bodt, and Richard Roll (2007) and Audra Boone and Harold Mulherin (2008) emphasize the value of potential competition in obtaining a good offer from a buyer.

2 "Middle market" transactions are typically defined as those between $\$ 50$ million and $\$ 500$ million. See also Wasserstein (2001), and also see Boone and Mulherin (2007a,b) for a detailed breakdown of actual sales methods.

3 "Auction Process Roundtable", Mergers and Acquisitions, December 2006, pp. 31-32.

Similarly, several large petrochemical companies are known for trying to maintain reputations for refusing to enter auctions either for buying businesses or for supplying products, at the same time as they sell businesses using auctions and procure supplies through "reverse" e-commerce auctions wherever possible.

${ }^{4}$ Wasserstein (2001) writes "It can be helpful to think of the range of possibilities in terms of two types - the classic... auction and the negotiated sale." In a negotiated sale a seller commonly agrees to a price with a single bidder while retaining the right to talk subsequently to other bidders according to a "go shop" agreement that gives it a limited amount of time to find a better offer; the agreement does not usually permit the seller to subsidize a new bidder to compete, and the original bidder retains the right to beat any new bidder's offers.

${ }^{5}$ Obvious examples are fine art and housing - see the conclusion.
} 
price above a buyer's minimum possible value.

Our central result is that the straightforward, level-playing-field competition that an auction creates is usually more profitable for a seller than a sequential process, even though the sequential mechanism is always more efficient in expectation (as measured by the winner's expected value less expected aggregate entry costs). Bidders, by contrast, usually prefer to subvert an auction by making pre-emptive "jump bids" when they can.

The sequential process is more efficient because although it attracts fewer bidders in expectation, it attracts more bidders when those bidders are most valuable - the existence or absence of early bids informs subsequent entry decisions and attracts additional bidders when the early ones turn out to be weak. But buyers' ability to make pre-emptive jump bids, which inefficiently deter too many potential rivals from entering, harms the seller. ${ }^{6}$

We identify four factors that may cause the expected revenue between the auction and the sequential mechanism to differ. The first three all unambiguously favor the auction. Two of these factors are fairly straightforward. First, even in the most favorable circumstances, a sequential process could only be superior if the queue of potential bidders is sufficiently much longer than the number that would compete in an auction. Second, in a sequential mechanism bidders who deter entry choose a price where the expected distribution of winning values is such that an additional entrant would expect to earn zero. By contrast, except in a knife-edge break-even case, bidders deterred from an auction face a distribution of winning values that make entry strictly unprofitable.

These two factors would be nullified with an infinite stream of potential bidders, and when parameters are such that the expected profits of the marginal bidder who does not enter the auction is exactly zero. The third factor is therefore crucial: the value of the winning bidder is generally less dispersed in the sequential process, because that process is more likely to attract one high-value bidder but will never attract more than one. But entrants prefer more dispersion in the value they have to beat, because dispersion makes the entrant's option to buy more valuable - this is just the standard consumer-theory result that consumers prefer more random prices. Therefore, the expected value of the top bidder in the auction must be higher than in the sequential mechanism to deter entry.

Thus, contrary to our usual instinct that auctions are profitable because they are efficient,

\footnotetext{
${ }^{6}$ Michael Fishman (1988) considered a model with two potential bidders, both of whom would have participated in an auction. In this case, a pre-emptive offer could deter entry by the second bidder but a sequential mechanism would not increase the number of bidders.

David Hirshleifer and Ivan Png (1989), Kent Daniel and Hirshleifer (1998), and Robert Easley and Rafael Tenorio (2004) emphasised jump bidding in the context of bidding costs (rather than costs of entry). Among the large theoretical literature on endogenous entry into auctions, see McAfee and McMillan (1987), Ronald Harstad (1990, 2003), McAfee, Dan Vincent, Mike Williams and Melanie Williams Havens (1993), Burguet and Joszef Sakovics (1996), Menezes and Monteiro (2000), Kate Larson and Tuomas Sandholm (2001), and the references therein.
} 
it is precisely the inefficiency of the auction - that entry into it is relatively ill-informed and therefore leads to a more random outcome - that makes it more profitable for the seller.

These three factors all speak to the superiority of the auction in generating entry, and each factor provides a separate reason why the expected value of the winner in the auction must exceed the expected value of the winner in the sequential mechanism. But the seller ultimately cares about the expected price paid, and the comparison of expected prices is a somewhat different question. The fourth factor, then, involves the gap between expected winning values and expected revenues, and this can work either for or against auctions.

However, we show that for typical demand specifications a higher expected winner's value directly implies higher expected revenue. More generally, we will see that the fourth factor (whatever its sign) is only significant when the third factor (which always favours the auction) is large. So an auction is generally better for a seller.

Why do bidders capture more than 100 percent of the extra rents created by the sequential mechanism? We will see that pre-emptive bidding is crucial: jump-bidding allows buyers to choose partial-pooling deterrence equilibria which over-deter entry relative to the social optimum. Although the information that bidders signal makes the sequential mechanism more efficient than the auction, the over-deterrence transfers enough rents to the bidders that sellers generally prefer auctions even when there is an infinite stream of potential buyers. With fewer potential buyers even efficient signalling can hurt sellers, because there is less potential to induce additional entry when early bidders are weak, so bidders earn some scarcity rents in a sequential mechanism even when there are more of them than would enter an auction.

With enough potential bidders, a sequential mechanism in which jump-bidding is prohibited may be desirable from the seller's viewpoint, because this retains the efficiency advantages of a sequential process while curtailing over-deterrence. But in markets such as that for corporate takeovers, it is generally the buyers who name prices, and pre-emptive jump bids are common.

Our paper is not primarily about "optimal" mechanisms. Part of the appeal of the auction is that the competition it creates allows the seller to do well independent of any knowledge of bidder values or any ability to exploit that knowledge. In our model, if the seller has enough information and commitment power to compute and charge optimal entrance fees and subsidies, it can run an efficient sequential procedure that extracts all buyers' surplus. ${ }^{7}$ More generally, if the seller can opportunistically subsidize entry it can

\footnotetext{
${ }^{7}$ See section VIIA. Our model (in which buyers have no information about their values before entering) is similar to a special case of Jacques Cremer, Yossi Spiegel, and Charles Zheng (forthcoming), though our model, unlike theirs, assumes the number of potential bidders is unknown. See also John Riley and Richard Zeckhauser (1983), Preston McAfee and John McMillan (1987, 1988), Roberto Burguet (1996), Egil Kjerstad and Steinar Vagstad (2000), Flavio Menezes and Paulo Monteiro (2000), Paul Milgrom (2004),
} 
increase expected revenue - mainly through the threat to subsidize. This both prompts stronger types of current bidders to make higher deterring offers, and prevents some of the socially excessive deterrence - so in many cases subsidies never actually need to be paid. But the sequential mechanism with subsidies can only be more profitable than an auction when the seller both has sufficient information and power to set the subsidies optimally and has enough potential bidders. And if buyers can threaten to withdraw if the seller seeks additional bids, the auction's advantage increases - buyers who arrive in sequence and can make credible take-it-or-leave-it offers can extract all the surplus.

In sum, the auction looks more profitable than practical versions of the sequential mechanism: absent extreme power on either side, sellers will generally prefer auctions and buyers will generally prefer sequential mechanisms.

The efficiency implications of our model should be viewed with care. While the model suggests the sequential mechanism is more efficient than the auction, this may reflect the model's narrow view of efficiency. First, because the sequential mechanism gives more surplus to the earliest bidders, potential entrants may dissipate their surplus in a race to the front of the queue. In this case, net social surplus will equal seller revenue. And second, even if bidders' rents are not dissipated in this way, mechanisms that give sellers a greater share of the value of the asset sold provide greater incentives to create valuable assets. So since the auction usually raises more revenue, it may well be more socially efficient overall.

We begin (in section I) with a model of a random number of symmetric risk-neutral potential bidders with search costs of finding out their (private) values of, for example, a company for sale. ${ }^{8}$ Section II solves for equilibrium behavior in the auction and in the sequential mechanism. We show that auctions are less efficient (section III) but likely to raise more revenue (section IV) than sequential bidding, and explain why. While it is possible to design examples where bidders prefer auctions, they typically prefer sequential processes (section $\mathrm{V})$.

Section VI shows our results are robust to simple modifications of our two basic sales processes, although the sequential mechanism becomes more attractive to sellers if buyers can be prevented from jump bidding. We also show that our results extend straightforwardly to simple common-value settings. In section VII we consider how bidding subsidies and other simple tactics such as lock-ups, break-up fees, and matching rights can be used by sellers to improve their expected revenue from the sequential mechanism. Section VIII concludes.

and Cremer, Spiegel, and Zheng (2007) and for discussions of optimal mechanisms in related contexts. See Paul Klemperer (1999, 2004), Vijay Krishna (2002), Milgrom (2004), and Menezes and Monteiro (2005) for syntheses of a large fraction of the auction literature.

${ }^{8}$ Equivalently, symmetric risk-neutral potential suppliers can make costly investments which yield (private) costs of selling to a procurer. 


\section{The Model}

We compare two mechanisms for selling an asset for which there is a queue of risk-neutral potential buyers. The probability that at least $j$ potential bidders exist, given the existence of at least $j-1$, is $\rho_{j}, 0 \leq \rho_{j} \leq 1$. We write $\left\{\rho_{j}\right\}_{j=1}^{\infty}$ for $\rho_{1}, \rho_{2}, \rho_{3}, \ldots$. Each buyer decides in turn whether or not to pay a cost $c$ to enter the sales mechanism. If it enters, it then immediately learns its own private value, which is drawn independently from the distribution $F(v)$ with a continuous density $f(v)$. Without any loss of generality, assume $F(\underline{v})=0$, $F(\bar{v})=1, \underline{v}$ equals the seller's value, and $\bar{v} \leqslant \infty$. All this is common knowledge among the buyers (the seller needs no knowledge of $F(\cdot)$, c, or $\left.\left\{\rho_{j}\right\}_{j=1}^{\infty}\right)$.

In the Auction mechanism, players cannot make any credible bid commitments until after entry stops. So when potential buyers make their entry decisions they observe only how many bidders have entered thus far. When entry has stopped, there is a standard English auction in which the bidder with the highest value wins and pays the value of the second highest.

Our Sequential mechanism is one that is commonly assumed for the sale of a business (see, e.g., Fishman (1988) and the subsequent literature based on his model). The first bidder simply chooses any initial bid. After any subsequent entry, the new entrant and the incumbent high bidder compete by raising the price (possibly making jump bids) until one or other quits; the surviver may then, if it wishes, make a further jump bid to deter subsequent potential entrant(s) before finding out whether any actually exist. Since (we will show ${ }^{9}$ ) all the equilibria of our game have identical outcomes and expected revenues, we assume for simplicity that any new entry results in the price first rising to the lower of the new entant's and the incumbent's values, with any jump bid only occurring after the lower-value of these bidders has quit. Bidders cannot lower bids that they have already made. Potential entrants observe all previous bids before they make their entry decisions, and when entry stops the current high bidder wins the asset at the price it bid.

We consider the perfect Nash equilibrium of the auction, which is unique except for knife-edge cases with two equilibria when the last bidder is indifferent to entering; in this case we take the worse case (the last bidder does not enter) for the auction.

We also consider all the perfect Nash equilibria of the sequential mechanism in which any buyer with a value greater than or equal to some constant cutoff value $v^{*}$ makes a high enough pre-emptive bid that all subsequent entry is deterred. ${ }^{10}$ However, we focus most attention on the unique perfect sequential equilibrium (as is standard in contexts like this

\footnotetext{
${ }^{9}$ See Remark 4.

${ }^{10}$ We will note later that there are other equilibria that are not (perfect) "symmetric cutoff" equilibria, but they do not seem very plausible.
} 
one - see below). ${ }^{11}$ We refer to the minimum value that deters entry in this equilibrium of the sequential mechanism as $V_{S}$. We will refer to the minimum value that would deter entry, if it were known by all potential entrants to be the bidder's value, as $V_{K} \cdot{ }^{12}$

To avoid trivialities, we assume there is at least one potential bidder and maybe more $\left(\rho_{1}=1\right.$ and $\left.\rho_{2}>0\right)$, and that $c$ is sufficiently small that at least two bidders would be attracted into an auction if they exist. The seller can demand a minimum price of $\underline{v}$ in both mechanisms but no higher. There is no discounting.

\section{Notation}

We write $v_{i}(k)$ for the actual $i^{\text {th }}$ highest value among $k$ bidders, and $n^{*}$ for the maximum number of entrants into the auction. We write $S(v)$ for the expected surplus of a bidder who competes in an ascending auction against a second bidder, when their values are drawn independently from $F(\cdot)$, conditional on the second bidder's value exceeding $v$; and $T(v)$ for the expected surplus of the (first) bidder, conditional on the second bidder's value equalling $v$. So $T(v)=\int_{x=v}^{\bar{v}}[x-v] f(x) d x$, and $S(v)=\frac{1}{1-F(v)} \int_{x=v}^{\bar{v}} T(x) f(x) d x .^{13}$

Finally, we write $M R(v) \equiv\left[v-\frac{1-F(v)}{f(v)}\right]$; using expected marginal revenues (EMRs), together with the standard Facts 1 and 2 below, is not needed for our proofs, but assists intuition and greatly simplifies calculations. ${ }^{14}$

\footnotetext{
${ }^{11}$ In a perfect sequential equilibrium, no bidder wishes to deviate from the equilibrium if a potential entrant who observes an out-of-equilibrium price would assume, if possible, that the bidder's type is among some set $\mathrm{K}$ (a subset of $[\underline{v}, \bar{v}]$ ) such that (i) all types in $\mathrm{K}$ would benefit from the deviation if it was then inferred that the bidder's type was in $\mathrm{K}$, and (ii) all types not in $\mathrm{K}$ would prefer not to deviate given the aforementioned inference.

This refinement is also variously called "credible" or "neologism-proof" or "F-G-P" after its developers (Sanford J. Grossman and Motty Perry (1986) and Joseph Farrell (1993)) - though Farrell's definition is very slightly different, this is unimportant here; see also Drew Fudenberg and Jean Tirole's (1991) standard text. Technically, we use the natural extension of the refinement to infinite strategy spaces; also a bit more than perfect sequential is needed to select a unique equilibrium when $\rho_{j}=1 \forall j$, and in that case we just use the limit of the (unique) perfect sequential equilibria as $\rho_{j} \rightarrow 1 \forall j$ (this is also the unique equilibrium that Farrell's definition chooses $\forall\left\{\rho_{j}\right\}_{j=1}^{\infty}$, because his definition requires all types in $\mathrm{K}$ would strictly benefit in part (i) above).

${ }^{12}$ The " $S$ " of $V_{S}$ signifies not only that it refers to the $S$ equential mechanism, but also that $V_{S}$ is this mechanism's revenue - or $V$ alue to the $S$ eller - in the important special case $\rho_{j}=1 \forall j$. The " $K^{\prime \prime}$ of $V_{K}$ signifies that it corresponds to bidders' values being Known.

${ }^{13}$ Note that $S(v)$ is not the surplus function that is often used in auction theory, i.e., it is not the surplus of a bidder with value $v$. We never need to compute $S(v)$ explicitly. It is also cumbersome to calculate it directly. However, it is easily calculated using Fact 1 below as the difference between the value of the bidder's gross winnings and its expected payments, that is (see note 16), $\int_{x=\underline{v}}^{\bar{v}}\{x-M R(x)\} f(x) P_{1}(x) d x$, in which $M R(x)=x-\frac{1-F(x)}{f(x)}$, and $P_{1}(x)$ is the probability with which the first bidder wins conditional on his value being $x$, that is, $\frac{F(x)-F(v)}{1-F(v)}$ for $x \geq v$. So $S(v)=\frac{1}{1-F(v)} \int_{x=v}^{\bar{v}}[1-F(x)][F(x)-F(v)] d x$.

${ }^{14}$ Thus if one graphs a "demand curve" with $v$ on the price axis, and $1-F(v)$ on the quantity axis, then $M R(v)$ is just the corresponding marginal revenue curve - a bidder whose value $v$ is drawn from $F(v)$ would on average buy $1-F(v)$ units at a take-it-or-leave-it price $v$, so has expected demand $1-F(v)$.

We make no assumptions on the $M R(v)$ function.

The mathematics of marginal revenue for auctions was introduced by Roger Myerson (1981); he coined the
} 
Fact 1 Consider any sales process that awards a good to one of a number of risk-neutral bidders, each of whom must learn its own private value for the good if it wishes to enter the bidding. Bidders' values are independently drawn from a distribution $F(v)$ with a continuous density $f(v) ; F(\underline{v})=0, F(\bar{v})=1$. If the minimum bid is $\underline{v}$, then the seller's expected revenue equals the EMR of the winning bidder. ${ }^{15}$

Fact 1 is the elementary extension of the standard Revenue Equivalence Theorem (Roger Myerson (1981), Riley and William Samuelson (1981)) to a possibly random number of bidders who must pay entry costs prior to bidding. ${ }^{16}$

Fact 2 For any value $\widehat{v}$, conditional on a bidder's value exceeding $\widehat{v}$, the bidder's $E M R$ equals $\widehat{v}^{17}$

terms "virtual valuation" and "virtual utility" in Myerson (1984). Jeremy Bulow and John Roberts (1989) first used the nomenclature "marginal revenue", and explained the connection with ordinary monopoly theory. This connection, and "MR analysis", were extended to a broader set of assumptions by Bulow and Klemperer (1996). $M R$ analysis simplifies the analysis in several ways.

First (when, as in our model, bidders' signals are independent) bidtakers' and bidders' surpluses depend only on the distribution of the winner's value and not on prices, or on auction form, or on which bidders actually participate: see Fact 1 and note 16 .

Second, it is often easier to work with the winner's marginal revenue than the price, since the price often depends upon other bidders' values, including in an ascending auction and in our sequential mechanism: see, e.g., the discussion of factor (b) below Lemma 5. Doing so also often avoids performing multiple integrations by parts: see, e.g., the calculations of bidders' surpluses in notes 13 and 18, which both use the fact that $M R(x) f(x)$ has a particularly easy form.

Third, crucially, working with marginal revenues permits state-by-state dominance arguments that do not apply to state-by-state revenues. This is exactly as in ordinary monopoly theory (because, of course, the marginal revenue of an additional unit sold accounts for both the direct effect on revenue (the price paid) and the indirect effect of the revenue lost from the lower price received for other units); in particular, a monopolist can raise the contribution to profits (price less cost) of some units by setting a higher or lower price than the optimum, but it will weakly lower the contribution to marginal revenue less marginal cost of every unit sold, since the optimum is set at $M R=M C$, so there is state-by-state dominance in $M R \mathrm{~s}$, but not in prices. See, e.g., the discussion of Lemma 4. See Bulow and Klemperer (1996) for another application to auction theory of state-by-state dominance in $M R \mathrm{~s}$ where there is no dominance in prices or revenues.

${ }^{15}$ That is, the seller's expected revenue equals $\int_{v=v}^{\bar{v}} M R(v) P(v) d v$, in which $P(v)$ is the probability density with which a bidder with value $v$ exists and wins the good. (So $P(v)=\sum_{j} Z_{j} P_{j}(v) f(v)$, in which $P_{j}(v)$ is the probability of potential bidder $j$ being awarded the good conditional on it entering and its value being $v$, and $Z_{j}$ is the probability that potential buyer $j$ both exists and enters $-Z_{j}$ is, of course, independent of $j$ 's value since it does not know it before entering.)

${ }^{16}$ It follows directly from the standard mathematics of revenue equivalence and marginal revenues, see e.g., Klemperer (2004; pp. 40-41, 46-47). That is, in the notation of note 15, the incentive-compatibility constraint implies that the expected post-entry surplus of any bidder, say $j$, who enters and learns its value is $v$ is $\int_{x=\underline{v}}^{v} P_{j}(x) d x$ (since if it finds its value is $\underline{v}$ it expects to earn zero surplus subsequent to entry) so its expected payment to the seller is $v P_{j}(v)-\int_{x=v}^{v} P_{j}(x) d x$. Its total expected payments conditional on entry are therefore $\int_{v=\underline{v}}^{\bar{v}} v P_{j}(v) f(v) d v-\int_{v=\underline{v}}^{\bar{v}} f(v) \int_{x=\underline{v}}^{v^{v}} P_{j}(x) d x d v$ which (integrating the second term by parts) equals $\int_{v=\underline{v}}^{\bar{v}} M R(v) P_{j}(v) f(v) d v$. Summing over all potential bidders times their probabilities of existing and entering yields the expression in note 15 .

${ }^{17}$ That is, $\frac{1}{1-F(\widehat{v})} \int_{x=\widehat{v}}^{\bar{v}}\left(x-\frac{1-F(x)}{f(x)}\right) f(x) d x=\widehat{v}$. This is mathematically equivalent to the fact that for a monopolist the integral of marginal revenue equals price times quantity and so the average marginal revenue of the buyers must equal the price. 


\section{Equilibria of the Mechanisms}

\section{A Equilibrium of the Auction}

The auction treats all entrants symmetrically, independent of their order of entry, so it is immediate that all of the first $n^{*}$ potential bidders enter, if they exist, and there is no subsequent entry, and

Lemma 1 The maximum number of entrants into the auction, $n^{*}$, is the largest integer, $n$, for which the expected surplus from being one of $n$ bidders in the auction strictly exceeds $c .{ }^{18}$

We do not need to compute the expected revenue explicitly, but it is easy to do so: it is the sum of expected revenue conditional on there being precisely $j$ bidders times the probability that precisely $j$ bidders exist, for all $j \in\left\{1,2, \ldots n^{*}-1\right\}$, plus the expected revenue when the maximum possible number of bidders, $n^{*}$, enters times the probability that at least $n^{*}$ potential bidders exist. So, using Fact 1 separately for each case

Remark 1 The Auction's expected revenue

$$
=\sum_{j=1}^{n^{*}-1}\left(\prod_{k=1}^{j} \rho_{k}\right)\left(1-\rho_{j+1}\right) \int_{x=\underline{v}}^{\bar{v}} j f(x) F^{j-1}(x) M R(x) d x+\left(\prod_{k=1}^{n^{*}} \rho_{k}\right) \int_{x=\underline{v}}^{\bar{v}} n^{*} f(x) F^{n^{*}-1}(x) M R(x) d x \text {. }
$$

Fact 1 also implies:

Remark 2 The Auction's expected revenue would be unaffected if we assumed any other standard auction, such as a first-price sealed-bid auction.

\section{B Equilibrium of the Sequential Mechanism}

In the equilibrium of the sequential mechanism, the first entrant makes a jump bid that is high enough to deter subsequent entry if its value exceeds some cutoff value, $v^{*}$, and otherwise bids the minimum price $\underline{v}$ - just as Fishman originally showed in his two-bidder version of this model. Any subsequent entrant whose value exceeds the current high bid competes with the current incumbent, and the price then rises until the lower-value of these two bidders quits at the point at which the price reaches its value. If it was the current incumbent who quit, the new entrant will then jump bid to the higher price that deters

\footnotetext{
${ }^{18}$ The winner's value will be $v_{1}(n)$ and in our (English) auction the price will be $v_{2}(n)$, so per-bidder expected surplus equals $\frac{1}{n}\left(E\left\{v_{1}(n)\right\}-E\left\{v_{2}(n)\right\}\right)$. This is most easily computed using Fact 1 that the expected auction revenue $\left(E\left\{v_{2}(n)\right\}\right)$ equals the $E M R$ of the winner. Since the probability density of the highest value among $n$ is $n f(x) F^{n-1}(x)$, per-bidder expected surplus $=\frac{1}{n} \int_{x=\underline{v}}^{\bar{v}} n f(x) F^{n-1}(x)\{x-M R(x)\} d x=$ $\int_{x=\underline{v}}^{\bar{v}}[1-F(x)] F^{n-1}(x) d x$.
} 
subsequent entry if its value exceeds the cutoff value, $v^{*}$, but will otherwise not raise the price further prior to any further entry. (If it was the entrant that quit, there is also no jump bid prior to further entry, in equilibrium, because the current incumbent's value must be below $v^{*}$.) If there is no jump bid, another potential bidder then enters, if one exists.

The deterrence value, $v^{*}$, cannot be lower than the value $V_{S}$ that satisfies $S\left(V_{S}\right)=c$ (because if it were, a prospective entrant would profit from entering against a deterring bid - entering and winning would deter all future entry, and the gross surplus from competing against an incumbent whose value is $v^{*}$ or higher is by definition $S\left(v^{*}\right)$, and clearly $S\left(v^{*}\right)>c$ if $\left.v^{*}<V_{S}\right)$. But an incumbent whose value is as low as $V_{S}$ can deter entry only if it is pooled with types with higher values - if its value was known to be as low as $V_{S}$, entry against it would be known to be profitable. So while $v^{*}=V_{S}$ is a perfect Nash equilibrium, there are other equilibria in which higher-value incumbents are separated.

The perfect constant-cutoff Nash equilibrium in which the fewest types deter entry is the one in which the only types who deter are those who would deter if their actual values were known (namely those whose values at least equal the value $V_{K}$ which satisfies $T\left(V_{K}\right)=c$ ). In these equilibria a bidder with value $V_{S}$ finds it too costly to pool with higher-value incumbents, and instead accommodates entry. ${ }^{19}$

However, as in Fishman's model, only the $v^{*}=V_{S}$ equilibrium is perfect sequential. In other equilibria, bidders with values above $V_{S}$ could gain from deviating to a bid that signals a value of (just) $V_{S}$ or more if (i) the potential entrant were then to infer the equilibrium deterring value is actually only $V_{S}$, and (ii) all other types of bidders would lose from making such a bid however the potential entrant were to respond. ${ }^{20}$ The logic of perfect-sequential equilibrium is that the potential entrant should make such an inference and a bid that signals a value of at least $V_{S}$ therefore does deter entry. A large literature argues that the unique perfect-sequential equilibrium is the only reasonable one in games like this one, ${ }^{21}$

\footnotetext{
${ }^{19}$ Equilibria with $v^{*}$ even higher than $V_{K}$ are ruled out by our assumption of a constant deterring value, and also fail not only the intuitive criterion, but also the weaker "test of dominated messages", even in any single period - see proof of Lemma 2 in Appendix. (There is also a plethora of perfect non-constant-cutoff equilibria, but it is straightforward using $M R$ analysis that the constant $V_{K}$ and constant $V_{S}$ equilibria define the upper and lower bounds in expected revenue among all these that pass the "test of dominated messages"; and there are even non-cutoff equilibria, for example, entry could be deterred only by some particular set of prices exceeding the price that would correspond to value $V_{S}$, but these seem particularly implausible.)

${ }^{20}$ In fact, a perfect sequential equilibrium requires only that all other types would lose from making such a bid if the potential entrant makes the inference that they are types above $V_{S}$ (see note 11), so the refinement is (even) more compelling than usual in our context.

${ }^{21}$ Fishman $(1988,1989)$ restricts attention to this equilibrium in his two-potential-bidders version of our model, contending that only this one is "credible". Andrei Shleifer and Robert Vishny (1986) claim "The case for the minimum bid equilibrium is compelling.... There is no basis for [any alternative] belief, since it is common knowledge that all types would like to [pay] the lowest possible price." And Mark Bagnoli, Roger Gordon, and Barton Lipman (1989) say "[We do not] clutter the text with details [of equilibria that are not perfect sequential]." Other authors who take similar views and pays scant attention to
} 
and we therefore focus primarily on this, $v^{*}=V_{S}$, equilibrium.

At any time, the (lowest) bid that deters further entry (i.e., the deterring price at that time) is such that a bidder with value $v^{*}$ is just indifferent about deviating to accommodating entry. That is, the bidder with value $v^{*}$ is indifferent between making a deterring bid and deviating to a strategy of never jump bidding but always bidding the lowest price possible to beat any challenger until entry closes, or until the price exceeds $v^{*}{ }^{22}$ Summarizing (see Appendix for the details of the proof, and for some simple examples):

Lemma 2 There exists a perfect Nash equilibrium of the Sequential mechanism in which any buyer with a value greater than or equal to $v^{*}$ makes a bid that deters all subsequent entry if and only if $v^{*} \in\left[V_{S}, V_{K}\right]$

$$
\begin{array}{cc}
\text { where } V_{S} \text { satisfies } \quad & S\left(V_{S}\right)=c, \\
\text { and } V_{K} \text { satisfies } & T\left(V_{K}\right)=c .
\end{array}
$$

In the unique perfect sequential equilibrium, $v^{*}=V_{S}$.

Example If $F(v)=v$ for $v \in[0,1]$ and $\rho$ is constant $\left(\rho_{j}=\rho \leq 1 \forall j>1\right)$, any new entrant whose value is $v^{*}$ or more deters entry by jump bidding to the price $v^{*}-\frac{1-\rho}{\rho} \log \left(\frac{1-\rho p}{1-\rho v^{*}}\right)$ $(>p)$, after defeating the existing incumbent at price $p$. (For the first entrant, $p=\underline{v}(=0$ here)). Expected revenue equals $\frac{v^{*}}{\rho}\left[1+\frac{(1-\rho)^{2}}{\left(1-\rho v^{*}\right)}\right]+\frac{2(1-\rho)}{\rho^{2}} \ln \left(1-\rho v^{*}\right) \cdot{ }^{23}$ In the unique perfect sequential equilibrium, $v^{*}=V_{S}=1-\sqrt{6 c}$. (Calculations are in the Appendix.)

We do not need to compute expected revenue explicitly, but it is straightforward to do so using $M R$ analysis: because (Fact 1) the seller's expected revenue equals the $E M R$ of the winner, we only need to know the distribution of the winner's value. (Because the deterring price generally changes over the course of the game - since it depends on the value

alternatives include Dan Bernhardt and David Scoones (1993), Kevin McCardle and S. Viswanathan (1994), and Yeon-Koo Che and Tracy Lewis (forthcoming), among others. Riley's (2001) authoritative survey of the signalling literature makes a strong general argument for focusing on the perfect sequential equilibrium. Finally, Andrew McLennan's (1985) argument for "justifiable" equilibrium, and note 20, provide additional arguments that this is the only natural equilibrium in our context.

A possible argument against the perfect sequential equilibrium is that the seller prefers the $v^{*}=$ $V_{K}$ equilibrium, and could perhaps in effect achieve it by slightly changing the game to one in which the only reasonable equilibrium is $v^{*}=V_{K}$. We therefore discuss this possibility in section VII.

${ }^{22}$ If a bidder with value $v^{*}$ is just indifferent about deviating, a bidder with a lower (higher) value would strictly gain (lose) by deviating, since higher-value types prefer strategies with higher probabilities of winning (and deviating strictly reduces the bidder's probability of winning). Not deviating therefore signals a value $\geq v^{*}$ and so successfully deters entry if $v^{*} \geq V_{S}$.

${ }^{23}$ The deterring price is increasing in both $p$ and $\rho$, and equals the deterring value, $v^{*}$, both in the limit as $p \rightarrow v^{*}$ and in the limit as $\rho \rightarrow 1$; as $\rho \rightarrow 0$, the deterring price equals price, $p$; as $\rho \rightarrow 0$ and 1 , expected revenue equals 0 and $v^{*}$, respectively - see Remark 5 . 
of the previous high bidder, and on the sequence of subsequent $\rho_{j}$ 's - calculating revenue by computing the actual price contingent on any sequence of bidders would be extremely messy.):

Remark 3 The Sequential mechanism's expected revenue

$$
=\sum_{j=1}^{\infty}\left(\prod_{k=1}^{j} \rho_{k}\right)\left(1-\rho_{j+1}\right) \int_{x=\underline{v}}^{v^{*}} j f(x) F^{j-1}(x) M R(x) d x+\sum_{j=1}^{\infty}\left(\prod_{k=1}^{j} \rho_{k}\right) F^{j-1}\left(v^{*}\right)\left(1-F\left(v^{*}\right)\right) v^{*} .
$$

(The first term sums (over $j$ ) the probability that the game will end with exactly $j$ bidders, all of whom have values less than $v^{*}$, times the winner's $E M R$ conditional on this event; this term may be negative. The second term is the probability that the winner's value exceeds $v^{*}$, times $v^{*}$, since (using Fact 2) the winner's EMR equals $v^{*}$ conditional on this event.)

Because Fact 1 means expected revenue depends only on the (expected) identity of the winner, assumptions that affect neither $v^{*}$ (and therefore also who enters) nor the fact that the highest actual entrant wins, are unimportant. In particular:

Remark 4 Expected revenues (and each potential buyer's expected surplus) would be unaffected by bidders knowing the number of potential entrants who actually exist in advance of any entry decisions (assuming it is common knowledge that they know this), and/or by the timing of entrants' jump-bidding (whether it is before, or during, or subsequent to competing with a current incumbent, or at all of these times). ${ }^{24}$

When there are an infinite number of potential bidders, the lowest deterring type must bid its full value, $v^{*}$, to deter, since it must be indifferent about not deterring and if it did not deter it would then surely face entry by someone with at least as high a value and so earn zero surplus. So the deterring price always equals $v^{*}$ in this case, and therefore (as can be confirmed directly using Remark 3):

Remark 5 If $\rho_{j}=1 \forall j$, expected revenue $=v^{*}$.

\section{Efficiency}

It is a standard result that the amount of entry into a private-value ascending auction is efficient (see Richard Engelbrecht-Wiggans (1993)). So, since in both our mechanisms the last potential entrant makes its entry decision based on the possibility of having to

\footnotetext{
${ }^{24}$ Actual prices depend upon these assumptions, of course. See the Example in the Appendix for an illustration. For the result about buyers' expected surpluses see note 16.
} 
compete in an ascending action with the strongest actual entrant, it is straightforward that all the entry decisions are socially efficient given the available information (details are in the Appendix):

Lemma 3 Conditional on the information available to a potential entrant, it makes the socially correct decision about whether to enter in either of the sales mechanisms.

Note that in the sequential mechanism the higher is $v^{*}$, the more efficient is the equilibrium. A social planner who could observe each bidder's value upon entry would choose entry until the highest value was such that the expected contribution of a new bidder was less than or equal to zero, that is, until a bidder was found with a value greater than or equal to $V_{K}$, since $\int_{x=V_{K}}^{\bar{v}}\left[x-V_{K}\right] f(x) d x-c=T\left(V_{K}\right)-c=0$. So the $V_{K}$ equilibrium is socially optimal.

In other equilibria, entrants who find out their values are in the range $\left[v^{*}, V_{K}\right)$ pool with those above $V_{K}$ and inefficiently prevent the further entry that would occur if their values were publicly observed. However, all these equilibria are more efficient than the auction, because they all provide prospective bidders with better information than the auction does. (A potential sequential bidder knows whether or not there is an incumbent bidder with a value in excess of $v^{*}$, and would never revise its entry decision if it were also told the number of previous entrants; a potential auction bidder, by contrast, knows only the number of other entrants, and might revise its decision if it were told whether or not there was an incumbent with a value of more than $v^{*}$.) Therefore, since all the entry decisions are socially efficient given the available information, the entry decision in the sequential mechanism is more efficient (in expectation) whenever the entry decisions in the two mechanisms differ. ${ }^{25}$ Both mechanisms select efficiently among all bidders who actually enter, so:

Proposition 1 The Sequential mechanism is more efficient than the Auction.

Since when there is an infinite number of potential bidders the deterring price always equals $v^{*}$ (see the discussion leading to Remark 5), the expected profit of any potential entrant, conditional on there being no previous bidder above the cutoff is $T\left(v^{*}\right)-c$ in this case, and (2) then implies that bidders all earn zero expected profits in the $V_{K}$ equilibrium. So the $V_{K}$ equilibrium is not only efficient but fully extractive in the "infinite potential bidder" case.

\footnotetext{
${ }^{25}$ Note when $v^{*}=V_{S}$ a potential entrant is just indifferent to entering, and so entry is a matter of indifference for efficiency as well. However, the entry decision is then strictly more efficient than in the auction when bidders cease entering the auction even though none have yet bid $V_{S}$.
} 


\section{Revenue}

The auction usually beats the sequential mechanism on revenue. We begin by showing (details in the Appendix) that:

Lemma 4 For any given value of $v^{*}$, if the auction is more profitable in expectation than the sequential mechanism for some sequence of $\left\{\rho_{j}\right\}_{j=1}^{\infty}$, then the auction is more profitable in expectation if any $\rho_{j}$ is reduced.

This result is not obvious in terms of actual prices, because the auction is not necessarily more profitable ex-post, if the actual number of entrants turns out to be low. For example, since the sequential mechanism encourages bidders to signal with high bids in early stages, conditional on only one entrant actually existing ex-post, the sequential mechanism earns more revenue than the auction (which then earns the minimum possible price). And, more generally, even if the number of potential bidders actually existing is known in advance (and is more than one), the sequential mechanism's realised price may be higher or lower than the auction's.

However, the intuition is obvious using EMR's (though we do not require $E M R$ 's for the proof). The reason is that conditional on $n^{*}$ or fewer bidders actually existing, the auction always selects the highest-value bidder possible, so always achieves a higher EMR than the sequential mechanism, ${ }^{26}$ while additional bidders beyond $n^{*}$ clearly have no effect on the auction but always (weakly) raise the sequential mechanism's EMR.

We can now show that the auction is superior in expected revenue to the sequential mechanism under likely conditions:

Proposition 2 The Auction is more profitable in expectation than the Sequential mechanism if (i) the equilibrium of the latter is its unique perfect sequential equilibrium and $S(\cdot)$ is convex (as it is for economists' most commonly used distributions of demand) and/or if (ii) $\prod_{j=3}^{n^{*}+1} \rho_{j}$ is sufficiently small (i.e., the probability of at least $n^{*}+1$ potential entrants existing, conditional on at least two existing, is sufficiently small).

Proof: Part (i): by Lemma 4, if the result holds for $\rho_{j}=1 \forall j$, it holds for all $\left\{\rho_{j}\right\}_{j=1}^{\infty} \leq 1$. Also, $S\left(V_{S}\right)=c \geq E\left\{S\left(v_{2}\left(n^{*}\right)\right)\right\} \geq S\left\{E\left(v_{2}\left(n^{*}\right)\right)\right\}$, in which the equality is the entry condition for the sequential mechanism (equation (1)), the first inequality is the entry condition for the auction $\left(\right.$ an $\left(n^{*}+1\right)^{s t}$ potential entrant would not want to enter

\footnotetext{
${ }^{26}$ This does not rely on any assumption about $M R \mathrm{~s}$. Since the auction selects its highest-value entrant, its $E M R$ equals its expected second-highest entrant's value (by Fact 2), which must in turn exceed the expected $M R$ of any bidder other than the auction winner, since $v>M R(v), \forall v<\bar{v}$.
} 
the auction given that it would compete against a bidder whose value exceeds the secondhighest of the $n^{*}$ previous entrants' values, $\left.v_{2}\left(n^{*}\right)\right)$, and the second inequality is Jensen's inequality (if $S(\cdot)$ is convex). So, since $S^{\prime}(\cdot)<0$, we have $V_{S} \leq E\left(v_{2}\left(n^{*}\right)\right)$. Since if $\rho_{j}=1 \forall j$, the expected revenue from the auction $=E\left(v_{2}\left(n^{*}\right)\right)$, and the revenue from the sequential mechanism $=v^{*}($ see Remark 5$), v^{*}=V_{S}$ suffices for the result.

Part (ii): recall from Remark 4 that the sequential mechanism's (and the auction's) expected revenue would be unaffected if the actual number of potential entrants was revealed to everyone prior to any entry decisions. So consider this case. Since the auction is strictly more profitable than the sequential mechanism in expectation when there are at least two, but not more than $n^{*}$, potential entrants (see note 26, or the proof of Lemma 4 - the auction, but not the sequential mechanism, always sells to the highest-value potential entrant in this event), this dominates the possibly-greater expected profitability of the sequential mechanism when there are more than $n^{*}$ potential entrants, if the relative probability of the latter event is sufficiently small. (When there is known to be just one potential entrant, both sales methods earn $\underline{v}$.)

There are three reasons why the auction is usually strictly more profitable than the sequential mechanism. These correspond to the facts that each of the first three inequalities in the proof of part (i) (namely $\left\{\rho_{j}\right\}_{j=1}^{\infty} \leq 1, c \geq E\left\{S\left(v_{2}\left(n^{*}\right)\right)\right\}$, and $E\left\{S\left(v_{2}\left(n^{*}\right)\right)\right\} \geq$ $\left.S\left\{E\left(v_{2}\left(n^{*}\right)\right)\right\}\right)$ are usually strict; they also correspond to the factors listed in the introduction.

First, there is never an infinite stream of potential bidders in practice (i.e., $\rho_{j}<1$, for some $^{27} j>2$ ). Since the sequential mechanism only has an advantage when a long tail of bidders actually enters, reducing the likely number of potential bidders reduces its chance of beating the auction (recall Lemma 4).

Second, the jump-bids in the sequential mechanism are "fine-tuned" to make entry just barely unattractive to an additional bidder, while the expected profit of the marginal bidder who does not enter the auction is generally strictly negative (i.e., $c>E\left\{S\left(v_{2}\left(n^{*}\right)\right)\right\}$ ).

Third, surplus from entry conditional on the value of the second-highest bidder is likely to be convex (i.e., $\left.E\left\{S\left(v_{2}\left(n^{*}\right)\right)\right\}>S\left\{E\left(v_{2}\left(n^{*}\right)\right)\right\}\right)$. So since the value of the second-highest bidder is random, its expected value (which equals the auction's expected revenue) has to be higher to deter entry than if this value were fixed; by contrast, the sequential mechanism's cutoff value (which determines the marginal entrant's surplus from that mechanism) is fixed.

Why does the auction's randomness usually make it more profitable?

\footnotetext{
${ }^{27}$ We need $j>2$ so that there is positive probability that at least 2 , but not an infinity of, potential entrants exist (see the proofs of Proposition 2 part (ii) and Lemma 4).
} 
The reason the auction's randomness usually makes it more profitable, that is, the reason $S(v)$ is usually convex, is best understood by recognising that two separate factors determine how the condition that the marginal prospective entrant be unwilling to enter the mechanisms affects the mechanisms' relative profitabilities. These factors are (a) the standard consumer-theory result that the prospective entrant's surplus if it were to enter either mechanism would be convex in the value, $v$, of the bidder who wins assuming the prospective entrant stays out (the prospective entrant can be thought of as having the option to buy at the price $v$, which option becomes more valuable as the distribution of $v$ becomes more dispersed), i.e., $T(v)$ is convex; and (b) the relationship between the values of the winners of the mechanisms and the prices they pay.

Both factors (a) and (b) depend upon the fact that even if there were an infinite number of potential bidders, and the expected values of the winners of the two mechanisms were the same, the dispersion of values faced by a new entrant into the auction would be greater than the dispersion of values faced by a new entrant into the sequential mechanism. More precisely:

Lemma 5 If the expected value of the winner of the auction with $n \geq 2$ bidders equals that of the winner of a sequential mechanism with cutoff value $v^{*}$ and an infinite number of potential bidders, the distribution of the sequential-mechanism-winner's value second-order stochastically dominates that of the auction-winner's value in the sense of Michael Rothschild and Joseph Stiglitz (19\%0).

To understand this, see Figure 1 which pictures the case of uniform $F(\cdot)$. In this case, the sequential-mechanism-winner's value is drawn from a constant density truncated below $v^{*}$, while the auction-winner's value is drawn from the increasing function $F^{n^{*}}(\cdot)$. [INSERT FIGURE 1 HERE] So the truncated density must be the higher at $v^{*}$, since both densities integrate to 1 . It must therefore also be the lower at $\bar{v}$ if both densities have the same mean. So the densities cross just twice, and the truncated distribution is therefore less risky. Considering a general $F(\cdot)$ simply distorts this picture without affecting the "twocrossings" property (see proof of Lemma in Appendix). ${ }^{28}$

Factor (a), then, is that, conditional on the two processes having the same expected winning value, a new entrant would find the auction more attractive because its distribution of winning values is more dispersed. Equating the attractiveness of the two mechanisms by increasing the expected value of the winner of the auction would require adding more bidders, which would raise the expected second-highest value and so the expected revenue

\footnotetext{
${ }^{28}$ For intuition, observe that the sequential mechanism-winner's value is drawn from $F(\cdot)$ truncated at the fixed value $v^{*}$, while the auction-winner's value can be thought of as drawn from $F(\cdot)$ truncated at the random value $v_{2}\left(n^{*}\right)$.
} 
in the auction. Alternatively, reducing the expected value of the winner of the sequential mechanism would require reducing its cutoff value, and therefore its expected revenue. So factor (a) always favours the auction.

Factor (b) determines whether a greater dispersion of winning values leads to greater or lower prices, conditional on any given expected winning value. Since the expected revenue of any mechanism is the expected $M R$ of the winning bidder, greater dispersion favours (hurts) the auction if $M R$ is convex (concave) in $v$. For demand functions commonly used by economists, including linear, exponential, and constant elasticity, $M R(v)$ is affine, ${ }^{29}$ so factor (b) is irrelevant. Furthermore, factor (b) can only matter much if winners have very dispersed valuations. But more dispersed winners' valuations also increase the importance of factor (a) which unambiguously benefits the auction.

In short, all four factors (the first two inequalities of the proof of part (i) of proposition 2 , and both the factors that determine the third inequality of the proof) go in the same direction if $M R(v)$ is convex, and this is therefore a very easily sufficient condition for expected revenue to be greater in the auction than in the sequential mechanism.

A more formal way to understand why the auction's randomness usually makes it more profitable is to use directly the microeconomic theory result that any consumer's welfare is always convex in the prices she faces. So $T(v)$, the expected surplus of a bidder who competes against another bidder with a value of exactly $v$, is always convex. Of course, the auction's relative profitability depends upon the convexity of $S(v)$, that is, the expected surplus of a bidder who competes against another bidder with a value at least $v$. But since $S(v)=E\{T(w) \mid w \geq v\}$ and $v=E\{M R(w) \mid w \geq v\}$ (this is Fact 2), we can show that $S(v)$ is a convex transformation of $v$ if $T(v)$ is a convex transformation of $M R(v)$, i.e., if $M R(v)$ is a convex transformation of $-T(v)$. But because $T(v)$ is convex, $-T(v)$ is concave, so it easily suffices that $M R(v)$ is convex. That is (for proof see Appendix):

Lemma $6 S(v)$ is convex in $v$ if $M R(v)$ is convex in $v$.

\section{Examples of relative profitabilities of mechanisms}

\footnotetext{
${ }^{29}$ For all these cases, the ratio of the slope of $M R$ to the slope of (inverse) demand $(v)$ is constant (i.e., $\frac{d^{2}}{d v^{2}} M R(v)=0$ everywhere): for uniformly-distributed signals $\left(F(v)=\frac{v-\underline{v}}{\bar{v}-\underline{v}}\right)$, which generate linear demand, the ratio of the slope of $M R$ to the slope of demand $=\frac{1}{2}$; for constant-elasticity distributed signals $(F(v)=$ $\left.1-\left(\frac{v}{v}\right)^{\eta}, \eta<-1\right)$, the ratio $=\frac{\eta}{\eta+1} ;$ and for exponentially-distributed signals $\left(F(v)=1-e^{-\lambda(v-\underline{v})}\right)$, which generate log-linear demand, the ratio $=1$.

The condition $\frac{d^{2}}{d v^{2}} M R(v)=0$ is satisfied by any member of the generalised Pareto distribution.

Note that convexity of $M R(v)$ in $v$ (i.e., $\frac{d^{2}}{d v^{2}} M R(v) \geq 0$ ) is not the same as convexity of the marginal revenue curve as it is usually drawn (which corresponds to convexity in "quantity" $(1-F(v)$ ), rather than "price" $(v))$. MR convexity is equivalent to concavity in the inverse hazard rate $\left(\right.$ or $2\left(h^{\prime}(v)\right)^{2} \leq h(v) h^{\prime \prime}(v)$, in which $h(v) \equiv \frac{f(v)}{1-F(v)}=$ the hazard rate). It is not hard to show that if expected demand is convex (i.e., $\left.f^{\prime}(\cdot) \leq 0\right)$, a sufficient condition for $S(\cdot)$ to be convex is $h^{\prime}(\cdot) \geq 0$.
} 
As an example, consider bidders with valuations uniformly distributed on $[0,1]$, that is $F(v)=v$ for $v \in[0,1]$. This corresponds to bidders forming a linear demand curve $p=1-q$, in the limiting case where there are $m$ such bidders each demanding $1 / m$ units at their values, as $m \rightarrow \infty$. If $c=.06$, the auction would attract up to $n^{*}=3$ bidders and yield expected revenue of .50 if there are at least three potential bidders. A fourth bidder would have an expected loss of exactly .01 and so would not enter.

To have the same expected winner's value, even with an infinite supply of potential bidders, the sequential mechanism's cutoff, $v^{*}$, would need to be .50 - see Figure 1. But to reduce a new entrant's expected profits to -.01 , a bidder in the sequential mechanism would have to credibly signal only that its value exceeded $1-\sqrt{.3} \approx .452$ (because $S(1-\sqrt{.3})=.05$, so if $c=.06$ a new bidder would have an expected loss of $.01-$ the calculations for this example are developed in detail in the Appendix). So roughly .50 - .45 =.05 of the extra revenue of the auction over that from the sequential mechanism is attributable purely to "convexity of surplus": although the auction yields an expected winner's value of .75, the sequential mechanism only needs an expected winner's value of .726 to reduce an entrant's net profits to -.01, because its winner's value is less dispersed. Because $M R(v)=2 v-1$, with $M R$ neither concave nor convex, the difference in the expected value of the winner (here, between .75 and .726) translates linearly into twice that difference in expected revenues.

If bidders pool on jump bids that make a new entrant's expected profits 0 instead of -.01 , then the cutoff value is lowered to .40 (because $S(.4)=.06=c$, so $V_{S}=.4$ ), extending the auction's advantage by another .05. Finally, if there were only three potential bidders (so $\rho_{j}=1$ for $j \leq 3$ and zero otherwise), the "finite supply of bidders" reduces the sequential mechanism's expected revenue by .05 more, to about .35 while leaving the auction's revenue unchanged at .50.

Of course, by both choosing $c$ so that an additional entrant is barely deterred in an auction (so $c=.05$ here) and also choosing $\rho_{j}=1 \forall j$ the last two effects are nullified. But even then, for the seller to prefer the sequential mechanism, the lower dispersion of the sequential mechanism's high value (worth the difference between .50 and .45 in the above example) must be compensated by concavity in the $M R$ function. However, $M R$ concavity only matters to the extent that the winning values in the auction and sequential mechanism differ. And the greater these differences, caused by the auction's greater dispersion, the greater the auction's advantage in expected winning value must be, making it that much harder for any concavity to help the sequential mechanism enough to catch up - even ignoring the other two factors.

Nevertheless, it is possible to find examples in which the sequential mechanism does win - in particular by choosing a distribution with a marginal revenue function that is essentially flat at higher values (so that the higher expected winner's value does little for 
the auction) and that conveniently becomes sharply lower just below $V_{S}$ (so that the auction is disproportionately punished for low outcomes $)^{30}$ — and then combining this with a large stream of potential bidders and a carefully chosen $c$. For such an example, assume bidders are equally likely to have the values $0, \frac{8}{11}$, and 1 (or a continuous approximation to this three point distribution) and $\rho_{j}=1 \forall j$. The expected revenue from the sequential mechanism then exceeds the expected revenue from the auction if (but only if) $c \in\left(\frac{80}{1782}, \frac{81}{1782}\right)$, in which case $c$ is low enough that $V_{S}=\frac{8}{11}$ and yet high enough that only 3 bidders enter the auction, so the greater chance that revenue will be 0 in the auction matters more than the possibility that the auction's revenue will be $1 .^{31}$

If $v^{*}=V_{K}$ the sequential mechanism is both socially optimal and fully extractive, as we have seen in section III, and therefore it must beat the auction in expectation if (but only if) the number of potential bidders is sufficiently much greater than $n^{*}$.

In short, there is a reasonable presumption that the expected price is higher in the auction than in the sequential mechanism.

\section{Bidders' Surplus}

Since the seller's profits are usually higher in the auction, but social welfare is lower, bidders' surplus must usually be lower also. We now show that not only does this result usually hold for total bidders' surplus, but that it is even more likely to hold for the surplus of the first bidder to enter. So the casual-empirical observation that the first bidder will generally seek to pre-empt an auction is borne out. We begin by showing (see Appendix for details):

Lemma 7 More bidders enter the Auction, in expectation, than the Sequential mechanism if (i) the equilibrium of the latter is its unique perfect sequential equilibrium and/or if (ii) $\prod_{j=3}^{n^{*}+1} \rho_{j}$ is sufficiently small.

The intuition is that the sequential mechanism sorts bidders better, in that entry stops as soon as one bidder with a high enough value to deter future entrants is found, while

\footnotetext{
${ }^{30}$ The standard statistical distribution, $F(v)$, that comes closest to these desiderata is the Normal distribution, for which it is just barely possible for the sequential mechanism to win. But it can do so only if $c \in$ $(0.2821 \sigma, 0.2823 \sigma)$ (in which $\sigma$ is the standard deviation - we let $\underline{v}=-\infty$ ). Furthermore, the maximum amount by which the sequential mechanism's expected profits can exceed the auction's, for any values of the parameters $c, \mu, \sigma$, and $\left\{\rho_{j}\right\}$, is $0.001 \sigma$, whereas if $c$ is just below $.2821 \sigma$ the auction's expected revenue is greater by over 500 times as much, even if $\rho_{j}=1 \forall j$. A more compelling example requires accentuating the "hump" - as we do in the example below by inserting a large central atom.

${ }^{31}$ To calculate the continuous distribution analogue, note that a deterred entrant expects zero profits from entry if $v^{*}=V_{S}$, so a buyer with value $\frac{8}{11}$ enters with probability $\frac{11 c}{1-11 c}$. The expected value of the winner in the auction, .892, comfortably exceeds the expected value of the winner in the sequential mechanism (between .864 and .865 depending on $c$ ).
} 
the auction attracts a random number of high-value bidders and therefore on average needs more bidders to achieve the same degree of entry deterrence. We now have (see Appendix):

Lemma 8 The first bidder obtains a smaller fraction of the total bidder surplus, in expectation, in the Auction than in the Sequential mechanism if (i) the equilibrium of the latter is its unique perfect sequential equilibrium and/or if (ii) $\prod_{j=3}^{n^{*}+1} \rho_{j}$ is sufficiently small.

The intuition is that not only are there more bidders on average among whom to split the surplus in the auction (see the previous Lemma), but also the surplus is tilted towards the first bidder in the sequential mechanism, because that bidder sometimes deters others in that mechanism, while all of the first $n^{*}$ bidders always enter the auction if they exist. It follows straightforwardly from these lemmas and Propositions 1 and 2 that:

Proposition 3 The Auction yields lower total bidder surplus, lower surplus per participating bidder, and lower surplus of the first entrant, in expectation, than the Sequential mechanism if (i) the equilibrium of the latter is its unique perfect sequential equilibrium, and $S(\cdot)$ is convex and/or if (ii) $\prod_{j=3}^{n^{*}+1} \rho_{j}$ is sufficiently small.

If both conditions (i) and (ii) fail, and the sequential mechanism has $v^{*}=V_{K}$ when $\rho_{j}=1 \forall j$, the auction is more attractive to all bidders. It is also possible to find examples in which all bidders prefer the auction with $v^{*}=V_{S}$ when $\rho_{j}=1 \forall j$ (and $S(\cdot)$ is not convex), but parameters must be chosen very carefully - such examples are clearly even more restricted than those for which the seller prefers the sequential mechanism. ${ }^{32}$

In short, bidders, especially those "at the front of the queue" (who are the most influential), mostly prefer sequential mechanisms; our model supports the advice that bidders should avoid auctions if possible.

\section{Robustness}

There are many variants of our simple canonical models of auctions and sequential sales in reality. And which extensive form best represents any given real-world process is often unclear. So how robust are our results?

\footnotetext{
${ }^{32}$ The example we gave in the previous section, for which the seller preferred the sequential mechanism, is also one in which the auction is the most attractive mechanism for bidders in total surplus, surplus per participating bidder, and surplus for the first entrant. (If $\rho_{j}=1 \forall j$, the first bidder's expected surplus is $\frac{28}{297}-c$ and $\frac{27}{297}-c$ in the auction and the sequential mechanism, respectively.) Of course, the set of $\left\{\rho_{j}\right\}_{j=1}^{\infty}$ for which these statements hold is even smaller than the set for which the seller prefers the sequential mechanism.
} 


\section{A Common Values}

We have focused upon an independent private value model. However, the simplest common value version of our model gives essentially the same results:

To make things simple, assume exactly $N$ potential bidders exist, that is, $\rho_{j}=1$ for $j \leq N ; \rho_{N+1}=0$. We maintain all the other assumptions of our original model, except that we interpret the $j^{\text {th }}$ bidder's draw from $F(v)$ as its signal, not its value; instead, all bidders share a common value which equals the sum of all $N$ potential bidders' signals. For this subsection alone, we assume that the hazard rate $f(v) /(1-F(v))$ is weakly increasing in $v .^{33}$ It is straightforward that in the symmetric equilibrium of an ascending auction with $n$ bidders the winner's actual surplus equals the difference between the two highest signals, so the entry condition for the auction, and the computation of $n^{*}$, is exactly as before. Furthermore (1), that is, $S\left(v^{*}\right)=c$, defines a perfect sequential equilibrium of the sequential mechanism, as before, if $c$ is not too large. ${ }^{34}$ The equilibrium parallels that of the independent private value case; as before, deterring bids are determined so that a bidder with signal $v^{*}$ is indifferent between deterring and not deterring.

So it is easy to see that our result about profitability (Proposition 2) holds exactly as before. Furthermore, all that matters for efficiency is the expected number of bidders, so Lemma 7 suffices for the result that the sequential mechanism is the more efficient sales process (Proposition 1), and our result about bidders' preferences (Proposition 3) also follows.

Calculation of equilibrium (and our results) remains straightforward when there is a random number of bidders in a "sum-of-signals" model, so long as the existence of an additional bidder always weakly increases the expected value of the asset, regardless of the bidder's signal. This would be true if, for example, the common value was the sum of the signals of all those potential bidders who exist and either $\underline{v} \geq \rho_{j} E(v) \forall j$, or $\rho_{j}$ is (weakly) increasing and $\underline{v} \geq 0$. (If a new entrant appearing and paying for a signal could reduce the asset's expected value, the entrant might be unwilling to top the current bid even if it's signal exceeded the incumbent's; so the sequential mechanism's winner might not be the bidder with the highest signal, and the incumbent's signal would no longer be a sufficient statistic for determining whether further entry would be deterred.)

\footnotetext{
${ }^{33}$ Bulow and Klemperer (2002) explain the importance of this assumption in common-value models, and provide additional information about their solution.

${ }^{34}$ We require that $S\left(v^{*}\right)=c$ yields $v^{*} \geq E(v)$. Otherwise, there are complications akin to those for $\rho_{j} \in(0,1)$ that we discuss later in this subsection.
} 


\section{B Simultaneous (Random) Entry into the Auction}

No important result is affected if potential bidders make simultaneous, instead of sequential, entry decisions into the auction. This is true whether we assume as in, e.g., Dan Levin and James L. Smith (1994), that potential bidders know the actual number of potential entrants when they make their entry decisions, or we assume potential bidders only know the distribution of the number of other potential entrants when they make their decisions.

The logic of Proposition 2 holds exactly as before: because the second-highest value in the auction is random, the auction price must be higher than the sequential mechanism's price to deter entry, if $S(\cdot)$ is convex. ${ }^{35}$ And since the random-entry auction is less efficient than the auction of our basic model (bidders have less information when they make their entry decisions), the auction remains less efficient than the sequential mechanism (Proposition 1), and Proposition 3 also follows.

\section{Soft-closing Auctions}

A seller may lack the ability or desire to commit to closing an auction if none of the initial entrants bids high enough. Assuming they have the ability to jump bid prior to any further entry, then if none of the initial bidders signals a value of at least $v^{*}$, an additional bidder or group of bidders (if any exist) will enter in a second round, and so on, until either there are no more potential entrants, or at least one bidder has a value exceeding $v^{*}$ and offers a deterring price.

It is easy to check that the expected revenue from such a "soft-closing" auction may be either higher or lower than in our basic auction, depending on parameters. ${ }^{36}$ Furthermore, this auction is always weakly more profitable and less efficient, in expectation, than the sequential mechanism: when only one bidder enters the "soft-closing" auction at a time, the mechanisms are identical, and when more than one bidder enters at a time, the auction has lower efficiency, but higher expected revenue, because it will attract at least as many if not more bidders than the sequential mechanism, and it may attract more than one bidder with a value in excess of $V_{S} \cdot{ }^{37}$

\footnotetext{
${ }^{35}$ The proof is essentially unchanged if we simply replace $v_{2}\left(n^{*}\right)$ by the actual second-highest value of whatever (random) number of bidders actually enter. The random-entry auction may be either more or less profitable than the auction of our basic model. David Reiley (2005) shows internet auctions are better modeled by random than by deterministic entry.

${ }^{36}$ For example, assume that there are an infinite number of potential bidders, each with values uniform on $[0,1]$. Let $c$ be close to $2 / 27$. Then the basic auction will attract three bidders and have expected revenue of $1 / 2$. The sequential mechanism would yield $V_{S}=1 / 3$. If $c$ is just over $2 / 27$, the hybrid auction will attract two bidders at a time until at least one is willing to pay $1 / 3$ or more, and expected revenue is $4 / 9$. If $c$ is just under $2 / 27$ the hybrid auction will attract three bidders at a time until at least one is willing to pay $1 / 3$ or more and expected revenue is $7 / 13$.

${ }^{37}$ The mechanisms yield different prices only when more than one bidder enters simultaneously in the last
} 


\section{Sequential Mechanisms Without Jump Bidding}

One assumption that does importantly affect our profitability comparisons is that entrants into the sequential mechanism can make jump bids to scare off subsequent entry.

The assumption is unimportant for efficiency. The greater expected efficiency of the sequential mechanism relative to the auction is due entirely to the information revealed by bidders competing until there is a single survivor prior to any further entry; the extra information prospective entrants learn by observing pre-emptive jump bids (or their absence), contributes nothing additional:

Proposition 4 The expected efficiency of the unique perfect sequential equilibrium of the Sequential mechanism would be unaffected if jump bids were not possible.

Proof: Absent jump bidding, potential entrants' information about the incumbent's value is only that it exceeds the value of the second-highest-value entrant to date, which the competition between the bidders allows it to observe. So entry will continue after the entry of the first bidder with a value above $V_{S}$. However, entry that takes place while there is just one bidder whose value exceeds $V_{S}$ is on average neutral for efficiency, since revealing only that the incumbent's value exceeds $V_{S}$ would leave potential entrants indifferent about entering, and potential entrants make the socially correct decisions given their information - see Lemma 3. Conditional on there having been two entrants whose values exceed $V_{S}$, so that the higher of these two bidders' values must be drawn from a distribution of $F(\cdot)$ truncated somewhere above $V_{S}$, further entry is socially undesirable. But as soon as two such bidders have entered, the price will anyway be driven up to $V_{S}$ or higher, thus deterring all further entry even without jump bidding.

But although jump bids are unimportant for total surplus, they play a crucial role in transferring it from the sellers to the buyers. When there are no rents to be earned from bidder scarcity $\left(\rho_{j}=1 \forall j\right)$ bidder profits are entirely due to the ability to make jump bids: absent jump bidding, a potential entrant knows only that the current incumbent's value exceeds the actual value of the second-highest-value entrant to date. So entry will continue until the value of the second-highest-value entrant is at least $V_{S}$, at which point

round of the auction. Since no bidders prior to this round have values exceeding $V_{S}$, the logic of Step 1 of the proof of Lemma 4 applies to this group of bidders. (As usual, the sequential mechanism's price in some states exceeds the auction's price. Also as usual, Facts 1 and 2 provide a quicker proof: the mechanisms have different winners only when at least two auction entrants' values exceed $V_{S}$. The auction winner's value then exceeds at least one other value above $V_{S}$, so its $E M R$ exceeds $V_{S}$, while the sequential mechanism's winner's $E M R$ equals $V_{S}$ in this case. So the auction wins.)

Another possible assumption is that bidders in the soft-closing auction cannot jump-bid prior to further entry. In this case, too, the new procedure may be more or less profitable in expectation than the basic auction, but is always more profitable in expectation than the (basic) sequential mechanism. 
the competition between the two highest-value entrants will demonstrate that at least one has a value above $V_{S}$, and there will be no subsequent entry. ${ }^{38}$ So, with an infinite supply of potential entrants, each new entrant knows it will win only if and when it beats one bidder whose value exceeds $V_{S}$. So it expects to earn zero profits (by equation (1)), that is:

Proposition 5 If jump bids were not possible in the Sequential mechanism, and there is an infinite supply of potential entrants, all bidders would earn zero surplus.

Because the "no jump bidding" mechanism would be both fully extractive (when $\rho_{j}=$ $1 \forall j$ ) and as efficient as the perfect sequential equilibrium of our basic sequential mechanism, which is in turn more efficient than the auction, it must yield higher expected revenue than the auction in this case. (Of course, the auction remains more profitable if sufficiently few potential entrants are expected - Part (ii) of Proposition 2 holds exactly as before.)

The reason jump bidding is so profitable for buyers is that it allows them to partially pool; many buyers who would not be able to deter entry if their values were known are able to do so by pooling with higher-value buyers. The perfect sequential equilibrium maximizes the size of the pool. By doing so, it also minimizes the cost of signaling to those bidders who would anyway be able to deter. From the seller's viewpoint, the cost of this strategic signalling outweighs the efficiency advantages of the sequential mechanism.

Observe that a special case of our model is equivalent to one in which all potential purchasers are initially present, if $F(\cdot)$ has sufficient dispersion that no one will ever bid without first paying the cost, $c$, to learn its value, and if the "auction mechanism" (but not the sequential mechanism) prohibits any learning of values after the bidding has begun. So our results here closely parallel those of Olivier Compte and Philippe Jehiel (2007) who model a fixed number of bidders, some of whom know their values for an object, while others are initially uninformed. They find that if there are sufficiently many bidders, then allowing uninformed bidders to purchase information about their actual values during a continuous ascending auction is more profitable than permitting them to buy such information only prior to the auction - in other words, in this context in which jump bids are not permitted, a "sequential" process is more profitable than a simultaneous auction. Leonardo Rezende (2005) and Eric Rasmusen (2006) obtain similar results.

So if the number of potential entrants is sufficiently large, running a sequential process at the same time as prohibiting jump bidding might be a seller's best option - if this is practical to implement.

\footnotetext{
${ }^{38}$ The expected number of entrants in the sequential mechanism without jump bids is therefore twice what it would be if jump bidding were possible (if $\rho_{j}=1 \forall j$ ).
} 


\section{E Buyers' Bargaining Power}

Buyers may be able to improve their position, and reduce expected revenues in the sequential mechanism, if they can build a reputation for exiting if an offer they make is not accepted. In the extreme case where sequential buyers can all fully commit to making take-it-or-leave-it offers, and $\rho_{j}=0$ for at least one (perhaps large) $j$, the unique subgame-perfect equilibrium is for the first bidder to make an offer of $\underline{v}$ with the seller accepting. (The game is trivial to solve recursively.) This mechanism obviously minimizes seller surplus and, if $v-M R(v)$ is weakly decreasing in $v$ (that is, the hazard rate $f(v) /(1-F(v))$ is weakly increasing in $v$ ), maximizes buyers' expected surplus. ${ }^{39}$

The more general principle is that if there is a high enough chance that a buyer will leave, then the seller may be forced to accept a price that would not deter future bidders, because of the risk of losing the current bidder. The increase in buyer's surplus from the lower price plus the efficiency loss from reduced entry causes a double hit to the seller.

If it is easier to credibly threaten to withdraw if a seller pursues new entrants in a sequential mechanism than to withdraw in the middle of bidding in an auction, this is another reason for sellers to prefer auctions.

\section{F Other Assumptions}

Remarks 2 and 4 illustrate that several assumptions about the extensive forms of the mechanisms are unimportant. Of course, other assumptions might matter more. ${ }^{40}$ But the bottom line is that varying our assumptions seems more likely to reinforce our results than to undermine them. The main caveat is that if the seller has the power to prevent jump bidding, and there are likely to be many bidders, the sequential mechanism looks very attractive to

\footnotetext{
${ }^{39}$ If $v-M R(v)$ is increasing in $v$, bidders who cannot resell may, for example, depending on bidding costs, do better in expectation, in aggregate, if the seller sets a reserve price above $\underline{v}$.

${ }^{40}$ For example, we have not considered (ex-ante) asymmetries among bidders. Both simple ascending auctions, and simple sequential procedures can perform very badly in this context. A first-price auction (or an Anglo-Dutch auction, see Klemperer (2002)) may perform better, but the premium on the seller having the power to implement more complex procedures may be large.

Also important is that a simple auction is perhaps more easily undermined, than a sequential process, by collusion, but the "soft closing" auction may mitigate this problem. (McAfee et al (1993) discusses collusion in a two-bidder version of our sequential mechanism.)

For the sale of corporate assets a preference for speed, discretion, or a long-term buyer (such as Buffett), or a financial buyer likely to retain current management, or a management buyout (where the management will prefer a low sales price) can make a sequential process preferable to some sellers.

Our model also ignores bidding costs (in Daniel and Hirshleifer (1998)'s early work on sequential models of takeovers (without entry costs) these make a simultaneous auction more efficient, as well as more profitable, than a sequential process), any other technological costs of choosing one selling mechanism over another (see, e.g., Ruqu Wang (1993, 1995, 1998) and Michael Arnold and Steven Lippman (1995)); legal issues (see, e.g., Peter Cramton and Alan Schwartz (1991), Ronald Gilson and Bernard Black (1995)); seller credibility (see, e.g., Guiseppe Lopomo (2000), David McAdams and Michael Schwarz (2007)); etc.
} 
it. On the other hand, if buyers have any countervailing power - in particular, the ability to credibly withdraw if additional buyers are sought - then the auction is especially attractive to sellers.

\section{Promoting Entry}

Sequential sales perform poorly for sellers, despite their relative efficiency, because auctions attract more entrants when they matter most. We now explore whether, or when, tactics to promote entry can enable sellers to capture greater revenues from a sequential mechanism.

\section{A Cash Subsidies}

If the seller knows $F(\cdot), c$, and $\left\{\rho_{j}\right\}_{j=1}^{\infty}$ and can pre-commit to a set of rules and the full common knowledge assumptions obtain for buyers, it can assure efficient entry and extract all surplus by using a sequence of entry fees and subsidies that give the buyers no expected surplus. ${ }^{41}$ This seems unrealistic. But it is natural to ask whether there is any simpler modification of the basic sequential mechanism that yields an outcome corresponding to the seller's "favorite" equilibrium $\left(v^{*}=V_{K}\right)$, while satisfying the perfect sequential equilibrium refinement that is usually imposed?

The answer is "yes", provided the seller also knows $F(\cdot), c$, and $\left\{\rho_{j}\right\}_{j=1}^{\infty}$. If the seller has the ability to partially subsidize (but not tax) new entry, this raises the signal (and therefore the price) needed to deter entry. In particular, if the size of the possible subsidy is chosen correctly, incumbent bidders with values between $V_{S}$ and $V_{K}$ are prevented from being able to pool with those above $V_{K}$. Even better, when the weaker types are separated from the stronger ones an unsubsidized entrant will compete against them. So while the threat of the subsidy is necessary, the subsidy never actually needs to be paid! The outcome is therefore exactly the same as the $V_{K}$ equilibrium we discussed earlier, and is therefore more profitable than the auction for $\rho_{j}=1 \forall j$. That is,

\footnotetext{
${ }^{41}$ The simplest efficient mechanism commits to a sequence of reserve prices for successive buyers, chosen so that any buyer with value $V_{K}$ is just willing to pay its reserve price rather than face additional entry. If entry ceases, a simple ascending auction is held between all those who have entered. To make the mechanism fully-extractive requires charging each successive entrant an entrance fee equal to his expected surplus from entry. See section 3.3 of Cremer, Spiegel, and Zheng (forthcoming), who also show that fully extractive efficient mechanisms can be implemented in considerably more general models than ours. (Cremer, Spiegel, and Zheng also generalise to allow for time discounting, so it can be efficient to have multiple entrants simultaneously, and generalise to bidders with different entry costs and with values drawn from different and non-independent distributions, so the optimal mechanism of an all-powerful buyer is then considerably more complex.)

If the seller can commit to subsidise future entrants, it can extract all surplus without needing to set reserve prices, as we now show.
} 
Proposition 6 Consider the Sequential mechanism with the additional feature that after any buyer enters and bids, the seller has the ability but not the obligation to offer to subsidise up to $c-S\left(V_{K}\right)$ of the next potential entrant's cost of finding out its value. The unique perfect sequential equilibrium of this mechanism is more profitable in expectation than the Auction for a set of sequences of $\left\{\rho_{j}\right\}_{j=1}^{\infty}$ that includes $\rho_{j}=1 \forall j$. Buyers with values below $V_{K}$ cannot deter entry, but no subsidies are paid in equilibrium.

Proof: If, when the current high bid is $p$, a single final buyer enters, the joint benefit to the new bidder and the seller is $v_{j}-p$ if $v_{j}>p$, and 0 otherwise, where $v_{j}$ is the new bidder's actual value, regardless of whether the incumbent outbids the entrant. So from (2) the seller would like to induce (at least) one additional entrant if $p<V_{K}$. Therefore, since the seller can if it wishes subsidise any potential bidder so that that bidder's total entry costs are no more than $S\left(V_{K}\right)$, a price below $V_{K}$ would only deter entry if it signalled that the deterring incumbent's value was at least $V_{K}$. Obviously, no bidder with a value below $V_{K}$ will be willing to set a price above $V_{K}$, so it follows that no bidder with a value below $V_{K}$ will deter entry.

As in Lemma 2, in the unique perfect sequential equilibrium, the pool of deterring bidders is as large as possible, so all those with values above $V_{K}$ will deter. Clearly no subsidy is then required to induce entry if the potential entrant faces only bidders who have not deterred (since an unsubsidized entrant earns at least zero in expectation if it will be able to buy at a price no more than $V_{K}$ ), and no feasible subsidy will induce entry once a deterring bid has been made. Therefore, no subsidies are actually paid in this equilibrium.

Furthermore, the discussion at the end of section III then implies the equilibrium is both efficient and fully extractive when $\rho_{j}=1 \forall j$, and so more profitable than the auction in this case. $\square$

Clearly the modified sequential mechanism will be more profitable than the auction for sequences of $\left\{\rho_{j}\right\}_{j=1}^{\infty}$ that are "close enough" to $\rho_{j}=1 \forall j$, but the argument of Proposition 2 part (ii) shows that for "sufficiently small" $\left\{\rho_{j}\right\}_{j=1}^{\infty}$ the auction remains more profitable. ${ }^{42}$

\footnotetext{
${ }^{42}$ Another way to encourage entry is to prohibit incumbent bidders from raising their bids in response to it. Entry will then continue until the price $V_{K}$ is bid. If $\rho_{j}=1 \forall j$, this is socially efficient and leaves no expected surplus for bidders, so achieves the maximum expected revenue obtainable from any mechanism. Aaron Edlin (2002) discusses regulatory regimes based on this principle. However, it may be hard to credibly commit to sticking to this strategy. It is also dangerous if there are likely to be few potential entrants: in this case, the fact that such a high price $\left(V_{K}\right)$ is required to deter entry means bidders may instead gamble on low-ball bids being enough to win.

This subsection's result that the modified sequential mechanism is more profitable in expectation than the auction for a set of $\left\{\rho_{j}\right\}_{j=1}^{\infty}$ that includes $\rho_{j}=1 \forall j$, applies to any perfect Nash equilibrium, not just to the unique perfect sequential equilibrium.
} 


\section{B Lock-ups, Break-up Fees, and Matching Rights}

The previous subsection shows that entry subsidies can make the sequential mechanism both more efficient and more profitable than the auction. By making entry subsidies larger still, the sequential mechanism can often be made even more profitable, by further raising the signal required to deter entry.

However, if the seller has the ability to offer larger subsidies than $c-S\left(V_{K}\right)$, then subsidies must sometimes actually be paid - even in circumstances in which a subsidy would not have had to be paid if large subsidies were not possible - because bidders who fear future high subsidies to attract entry against them may need to be paid to be persuaded to enter today. ${ }^{43}$ Furthermore, the gains to the seller from reducing buyer surplus are reduced by the inefficiency of the incremental entry induced by these larger subsidies.

The seller could do better than simply offering large subsidies if it could pre-commit to avoiding future inefficient subsidies. In particular, it could benefit from a provision that prohibited it from paying any further subsidies to additional bidders if the current entrant signalled a value of at least $V_{K}$.

Such a combination of a subsidy to a current entrant and a promise to limit future subsidies parallels the common practice of sellers of public companies of offering "lock-ups" that include a break-up fee (equivalent to cash paid out of corporate assets) and "matching rights" that prohibit subsidies to future bidders in return for a sufficiently high bid. ${ }^{44}$

So our analysis suggests a role for lock-up-like combinations of current subsidies and promises about future subsidies, but the details will depend not only on the bargaining power of the seller against any new entrant, but also on the specification of the bargaining protocol between the seller and the current incumbent (since bargaining between these actors can lead to even more efficient outcomes). This is beyond the scope of the current paper.

However, we are sceptical of the broad use of subsidies in practice. Subsidies can easily be abused by a seller who wishes to bias the process. It is not uncommon to see the board

\footnotetext{
${ }^{43}$ In particular, when large subsidies are feasible a first bidder with a value above $V_{K}$ may prefer to make the minimum allowable bid and risk entry if $\rho_{2}$ is small, rather than bid $V_{K}$ to deter entry (because a lower bid that simply signals a value of $V_{K}$ may not - by contrast with the low-subsidy case - be enough to deter entry); the second bidder may then require a subsidy since it may have to face future highly-subsidized entry (it will certainly require a subsidy if $\rho_{j}=1 \forall j>2$ ). The need to sometimes actually pay a subsidy means that in some examples the ability to offer subsidies above $c-S\left(V_{K}\right)$ does not help the seller in expectation.

${ }^{44} \mathrm{~A}$ break-up fee guarantees the bidder a fixed sum in return for making its offer, payable if the deal fails to be completed - typically because of a topping offer by another bidder - and are typically accompanied by "matching rights". Since the break-up fee is a sunk cost once agreed to, it only distorts an auction if the recipient makes an initial offer above its value in order to receive it. See Ian Ayres (1990). Che and Lewis (2007) show the merits of breakup fees in Fishman (1988)'s model. (Sometimes buyers will offer sellers break-up fees, for example, as protection against a deal collapsing because of antitrust problems. Break-up fees are limited to $1 \%$ of the value of the bid in the UK, but can be much higher in the US.) Related issues are discussed by Michael Rothkopf, Harstad and Yuhong Fu (2003).
} 
of a target company granting subsidies (with matching rights) to an initial bidder that has made a deal with management, effectively deterring other bidders. ${ }^{45}$ And potential first bidders may be deterred by the possibility of the board paying subsidies to a managementled counter-bid or other favored alternative bidder. ${ }^{46}$

Even putting aside both this moral hazard problem, and the problem of attracting nongenuine bidders who pocket subsidies without investigating serious bids, ${ }^{47}$ the tactics considered here depend sensitively on the seller's information. The basic sequential mechanism and the auction can be implemented by a seller who knows nothing about the distribution of bidders' values, or bidders' perception of that distribution, or their cost of entry. But the tactics here require knowledge of all these things. And with endogenous entry the implementation of an "optimal mechanism" is fraught with danger: there is a small difference between a tactic that extracts all surplus and one that discourages all entry. So while the ability to offer a limited special deal to a "white knight" involving paying its fees, or giving it cheap options or a lock-up, can increase expected revenue, this depends upon the seller being a revenue-maximiser with sufficient informational resources ${ }^{48}$ and commitment powers to fine-tune its use of these tactics.

In addition, of course, even with modifications, the sequential mechanism beats the auction only if there are "enough" potential bidders. All told, there is good justification for the U.S. legal system's strong encouragement of auctions for the sale of public companies (see Cramton and Schwartz (1991)).

\footnotetext{
${ }^{45}$ Paying break-up fees to initial bidders is especially suspect. Consider, for example, the recent $\$ 33$ billion buyout of hospital owner HCA, which gave the group that included management a $\$ 300$ million break-up fee and matching rights in return for an offer that exceeded the pre-takeover valuation by about $\$ 3$ billion. Since the management group was probably also better informed than any potential rival, it is no surprise that investment bankers were then unable to find a competing offer.

${ }^{46}$ For example, if $\rho_{j}=1 \forall j$ and the first potential bidder perceives any risk that future subsidies will be larger than optimal, it will never enter, since it would be forced to either bid above $V_{K}$ or to suffer subsidised competition.

A further concern arises if management can pay subsidies in shares. Giving shares is cheaper than paying cash, because the recipient values them more than the seller - either the recipient sells out at the sale price that would have resulted anyway, or the recipient is the final winner and so values them more than this, and because it gives the recipient a toe-hold advantage (see Bulow, Ming Huang and Klemperer (1999)). So management has a temptation to offer a subsidy in shares even against a bid of $V_{K}-$ but no bidder will then be prepared to make an original bid of $V_{K}$.

${ }^{47}$ Giving break-up fees and matching rights only in return for a "good" offer mitigate the second problem but without eliminating it (it is usually not hard for a winner to find an excuse to withdraw) and at the cost of possibly introducing inefficiency (see note 44).

${ }^{48} \mathrm{But}$ if the seller is thought to have too much information, for example, more information than the bidders about the probability of further potential entrants, then the current potential bidder may be reluctant to deal with the seller.
} 


\section{Conclusion}

Much academic and practitioner opinion argues that sellers benefit from the "level playing field" competition of a simultaneous auction. For example, Bulow and Klemperer (1996) show under mild conditions that even a simple ascending auction with no reserve price is more profitable than the best possible process that can be conducted with one fewer bidder. But models such as this assume no entry costs, so an auction is also most efficient. If participating in the sales process is costly, the case for auctions is less compelling, because sequential mechanisms are more efficient.

Nevertheless, as a practical matter, auctions generally work best for sellers. As a weapon for negotiating a price, the threat of refusing an offer and waiting for more competitors is less effective than actually inviting the competitors straight in - even though the latter strategy is more socially costly. Buyers, on the other hand, usually gain (in expectation) by disrupting an auction process and forcing sellers to deal with them sequentially. Why?

The auction has three clear advantages for the seller: first, it requires only a limited number of potential bidders to achieve its maximum expected revenue; the sequential mechanism's advantage in being able to consider more buyers if earlier offers are too low is only relevant if the number of potential bidders exceeds the number that would participate in an auction. Second, buyers in a sequential mechanism can make jump bids that just deter entry and so increase their expected profits at the the seller's expense. Third, the greater dispersion in the winner's value in the auction means its expected value must also be higher - and although it does not follow that the price it pays is necessarily higher, the greater entry means it usually will be.

So sellers only rarely benefit from the efficiencies created by sequential search.

The main exception is that if it is difficult for buyers to make credible public jump bids, a simple sequential mechanism may be more profitable than an auction if there are also sufficiently many potential buyers and the buyers have sufficiently high costs of collecting enough information to bid. This might help explain why sequential sales procedures are common for residential housing, where search costs, inspection fees, etc., may be high and where (in many jurisdictions) it is hard to commit to a firm offer. For more valuable properties and commercial real estate, search costs are a smaller fraction of values, the number of bidders may be smaller, and their abilities to make credible bids may be greater - consistent with the greater prevalence of auctions for these transactions. ${ }^{49}$

\footnotetext{
${ }^{49}$ Our model abstracts from several important issues in the sales of both companies (see note 40) and houses (in particular, there are flows of buyers and sellers into and out of the housing market so issues of timing are especially important).

Similarly, the reasons some art dealers argue that auctions can be less profitable than discreetly showing a significant work of art to potential buyers one at a time, negotiating with whoever shows interest, probably
} 
In takeover battles, however, the set of potential buyers is usually quite limited, and jump bids are routine, consistent with the evidence that sophisticated value-maximising sellers usually prefer auctions, while buyers more often prefer to pre-empt them if they can.

With credible jump bidding, unless the number of potential bidders is likely to be large and the seller has the information and the ability to enforce contracts including lock-ups, matching rights, and entry subsidies, etc., the auction is more profitable on average except under delicate conditions on demand curvature, bidding costs, and the supply of potential bidders; for the seller to prefer the sequential mechanism requires several stars to be aligned - and for the seller to realize that they are so. If the likely number of potential bidders is small, or if the seller has only limited information about valuations, entry costs, or the number of bidders, or needs to standardize procedures across many sales, as with some government entities, a simultaneous auction is the seller's best bet: it should structure the sales process (for example, by timing the release of critical information - see Wasserstein (2001)) so that bidders are unable or unwilling to make early bids. The preference for auctions should be particularly strong in the sale of public companies where jump bids can be made public and where, because of concerns about moral hazard, one might wish to restrict management in its ability to discriminate between bidders.

Taking a broader perspective, this paper and Bulow and Klemperer (1996) both show the power of competition. Bulow and Klemperer (1996) showed that the extra competition provided by a single extra bidder dominates the extra value of any clever negotiating strategies or regulatory schemes that might be designed to extract more rents from competing firms. The current paper shows that, except in rare cases, potential competition is not a good substitute for actual competition: the straightforward, level-playing-field competition that a simple auction creates is usually more profitable for a seller than a sequential procedure that sometimes attract more bidders, but prevents direct, simultaneous competition among all participants on equal terms.

lie outside our model. The publicity of an auction can create stigma (since sales are often associated with "the three D's" - divorce, (financial) distress, and death), attract unwelcome attention from tax authorities (so many private sales take place in Monaco or Liechtenstein), and undermine the common practice of commissioning a copy of the art sold to hang in its place (after selling the original in a different continent). (There may also be an agency problem: it is hard for a dealer to justify high fees if he merely consigns clients' assets to auction.) 


\section{References}

[1] Aktas, Nihat, de Bodt, Eric and Roll, Richard. 2007. "Negotiation Under the Threat of an Auction: Friendly Deals, Ex-Ante Competition and Bidder Returns." UCLA Anderson School of Management Working Paper \#19-07.

[2] Arnold, Michael A. and Steven A Lippman. 1995. "Selecting a Selling Institution: Auctions versus Sequential Search." Economic Inquiry, 33(1): 1-23.

[3] Ayres, Ian. 1990. "Analyzing Stock Lockups: Do Target Treasury Sales Foreclose or Facilitate Takeover Auctions?" Columbia Law Review, 90(3): 682-718.

[4] Bagnoli, Mark, Roger Gordon and Barton L. Lipman. 1989. "Stock Repurchase as a Takeover Defense." Review of Financial Studies, 2(3): 423-443.

[5] Bernhardt, Dan and David Scoones. 1993. "Promotion, Turnover, and Preemptive Wage Offers." American Economic Review, 83(4): 771-791.

[6] Boone, Audra L. and J. Harold Mulherin. 2007. "How Are Firms Sold?" Journal of Finance, 62(2): 847-875.

[7] Boone, Audra L. and J. Harold Mulherin. 2007. "Do Termination Provisions Truncate the Takeover Bidding Process?" Review of Financial Studies, 20(2): 461-489

[8] Boone, Audra L. and J. Harold Mulherin. 2008. "Do Auctions Induce a Winner's Curse? New Evidence from the Corporate Takeover Market." Journal of Financial Economics, $89(1): 1-19$.

[9] Bulow, Jeremy, Ming Huang, and Paul Kemperer. 1999. "Toeholds and Takeovers." Journal of Political Economy, 107(3): 427-54.

[10] Bulow, Jeremy, and Paul Klemperer. 1996. "Auctions versus Negotiations." American Economic Review, 86(1): 180-94.

[11] Bulow, Jeremy, and Paul Klemperer. 2002. "Prices and the Winner's Curse." Rand Journal of Economics, 33(1): 1-21.

[12] Bulow, Jeremy, and John Roberts. 1989. "The Simple Economics of Optimal Auctions." Journal of Political Economy, 97(5): 1060-90.

[13] Burguet, Roberto. 1996. "Optimal Repeated Procedures When Sellers are Learning About Costs." Journal of Economic Theory, 68: 440-455.

[14] Burguet, Roberto and Josef Sakovics. 1996. "Reserve Prices Without Commitment." Games and Economic Behavior, 15(2): 149-64.

[15] Che, Yeon-Koo and Tracy R. Lewis. 2007. "The Role of Lockups in Takeover Contests." Rand Journal of Economics, 38(3): 648-69.

[16] Cho, In-Koo and David M. Kreps. 1987. "Signalling Games and Stable Equilibria." Quarterly Journal of Economics, 102(2): 179-222. 
[17] Compte, Olivier, and Philippe Jehiel. 2007. "Auctions and Information Acquisition: Sealed-bid or Dynamic Formats?" Rand Journal of Economics, 38(2): 355-72.

[18] Cramton, Peter and Alan Schwartz. 1991. "Using Auction Theory to Inform Takeover Regulation." Journal of Law, Economics, and Organization, 7(1): 27-53.

[19] Cremer, Jacques, Yossi Spiegel, and Charles Zheng. 2007. "Optimal Search Auctions." Journal of Economic Theory, 134: 226-248.

[20] Cremer, Jacques, Yossi Spiegel, and Charles Zheng. Forthcoming. "Auctions with Costly Information Acquisition." Economic Theory.

[21] Daniel, Kent D. and David A. Hirshleifer. 1998. "A Theory of Costly Sequential Bidding." University of Michigan Business School Working Paper No. 98028.

[22] Easley, Robert F. and Rafael Tenorio. 2004. "Jump Bidding Strategies in Internet Auctions." Management Science, 50(10): 1407-19.

[23] Edlin, Aaron. 2002. "Stopping Above-Cost Predatory Pricing." Yale Law Journal, 111(4): 941-992.

[24] Engelbrecht-Wiggans, Richard. 1993. "Optimal Auctions Revisited." Games and Economic Behavior, 5(2): 227-39.

[25] Farrell, Joseph. 1993. "Meaning and Credibility in Cheap-Talk Games." Games and Economic Behavior, 5(4): 514-531

[26] Fishman, Michael J. 1988. "A Theory of Preemptive Takeover Bidding." Rand Journal of Economics, 19(1): 88-101.

[27] Fishman, Michael J. 1989. "Preemptive Bidding and the Role of the Medium of Exchange in Acquisitions." Journal of Finance, 44(1): 41-57.

[28] Fudenberg, Drew, and Jean Tirole. 1991 Game Theory. Cambridge, MA: MIT Press.

[29] Gilson, Ronald J., and Bernard Black. 1995. The Law and Finance of Corporate Acquisitions, second edition, Westbury, N.Y.: Foundation Press.

[30] Grossman, Sanford J. and Motty Perry. 1986. "Perfect Sequential Equilibrium." Journal of Economic Theory, 39(1): 97-119.

[31] Harstad, Ronald M. 1990. "Alternative Common-Value Auction Procedures: Revenue Comparisons with Free Entry." Journal of Political Economy, 98(2): 421-29.

[32] Harstad, Ronald M. 2003. "Selling without Reserve as the Content of Optimal Auctions." Olin Business School Working Paper 2003-01-001.

[33] Hirshleifer, David and Ivan Png. 1989. "Facilitation of Competing Bids and the Price of a Takeover Target." Review of Financial Studies, 2(4): 587-606.

[34] Jewitt, Ian. 1987. "Risk Aversion and the Choice Between Risky Prospects: The Preservation of Comparative Statics Results." Review of Economic Studies, 54(1): 73-85. 
[35] Karlin, Samuel. 1968. Total Positivity. Stanford, CA: Stanford University Press.

[36] Kjerstad, Egil, and Steinar Vagstad. 2000. "Procurement Auctions with Entry of Bidders." International Journal of Industrial Organization, 18(8): 1243-1257.

[37] Klemperer, Paul. 1999. "Auction Theory." Journal of Economic Surveys, 13(2): 227-86.

[38] Klemperer, Paul. 2002. "What Really Matters in Auction Design." Journal of Economic Perspectives, 16(1): 169-189.

[39] Klemperer, Paul. 2004. Auctions: Theory and Practice, Princeton, NJ: Princeton University Press.

[40] Krishna, Vijay. 2002. Auction Theory. New York, NY: Academic Press, US.

[41] Kreps, David M. 1990. A Course in Microeconomic Theory. Princeton, NJ: Princeton University Press.

[42] Larson, Kate and Sandholm, Tuomas. 2001. "Costly Valuation Computation in Auctions." In Proceedings of the $8^{\text {th }}$ Conference on Theoretical Aspects of Rationality about Knowledge, Siena, Italy. San Francisco, CA: Morgan Kaufmann Publishers Inc.: 16982.

[43] Levin, Dan and James L. Smith.1994. "Equilibrium in Auctions with Entry." American Economic Review, 84(3): 585-99.

[44] Lopomo, Giuseppe. 2001. "Optimality and Robustness of the English Auction." Games and Economic Behavior, 36(2): 219-240.

[45] McAdams, David, and Michael Schwarz. 2007. "Credible Sales Mechanisms and Intermediaries." American Economic Review, 97(1): 260-76.

[46] McAfee, R. Preston, and John McMillan. 1987. "Auctions with Entry." Economics Letters, 23(4), pp. 343-47.

[47] McAfee, R. Preston and John McMillan. 1988. "Search Mechanisms." Journal of Economic Theory, 44(1): 99-123.

[48] McAfee, R. Preston, Dan Vincent, Mike Williams, and Melanie Williams Havens. 1993. "Collusive Bidding in Hostile Takeovers." Journal of Economics and Management Strategy, 2(4): 449-482.

[49] McCardle, Kevin F. and S. Viswanathan. 1994. "The Direct Entry versus Takeover Decision and Stock Price Performance around Takeovers." Journal of Business, 67(1): $1-43$.

[50] McLennan, Andrew. 1985. "Justifiable Beliefs in Sequential Equilibrium." Econometrica, 53(4): 889-904

[51] Milgrom, Paul R. 2004. Putting Auction Theory to Work. Cambridge, UK: Cambridge University Press. 
[52] Menezes, Flavio M. and Paulo K. Monteiro. 2000. "Auctions with Endogenous Participation." Review of Economic Design, 5(1): 71-89.

[53] Menezes, Flavio M. and Paulo K. Monteiro. 2005. An Introduction to Auction Theory. Oxford, UK: Oxford University Press.

[54] Myerson, Roger B. 1981. "Optimal Auction Design." Mathematics of Operations Research, $6(1)$ : 58-73.

[55] Myerson, Roger B. 1984. "Two-Person Bargaining Problems with Incomplete Information." Econometrica, 52(2): 461-487.

[56] Rasmusen, Eric. 2006. "Strategic Implications of Uncertainty over One's Own Private Value in Auctions." Advances in Theoretical Economics, 6(1): Article 7.

[57] Reiley, David H. 2005. "Experimental Evidence on the Endogenous Entry of Bidders in Internet Auctions." In Amnon Rapoport and Rami Zwick (eds.), Experimental Business Research, Volume 2: Economic and Managerial Perspectives. Norwell, MA and Dordrect, The Netherlands: Kluwer Academic Publishers: 103-121.

[58] Rezende, Leonardo. 2005. "Mid-Auction Information Acquisition." University of Illinois mimeo. www.econ.puc-rio.br/lrezende/noise.pdf.

[59] Riley, John G. 2001. "Silver Signals: Twenty-Five Years of Screening and Signalling." Journal of Economic Literature, 39(2): 432-78.

[60] Riley, John G., and William F. Samuelson. 1981. "Optimal Auctions." American Economic Review, $71(3): 381-92$.

[61] Riley, John G. and Richard Zeckhauser. 1983. "Optimal Selling Strategies: When to Haggle, when to Hold Firm." Quarterly Journal of Economics, 98(2): 267-89.

[62] Rothschild, Michael and Joseph E. Stiglitz. 1970. "Increasing Risk I: A Definition." Journal of Economic Theory, 2(3): 225-43.

[63] Rothkopf, Michael H., Ronald M. Harstad, and Yuhong Fu. 2003. "Is Subsidizing Inefficient Bidders Actually Costly?" Management Science, 49(1): 71-84.

[64] Shleifer, Andrei and Vishny, Robert W. 1986. "Large Shareholders and Corporate Control." Journal of Political Economy, 94(3): 461-488.

[65] Wang, Ruqu. 1993. "Auctions versus Posted-Price Selling." American Economic Review, 83(4): 838-51.

[66] Wang, Ruqu. 1995. "Bargaining versus Posted-Price Selling." European Economic Review, 39(9): 1747-64.

[67] Wang, Ruqu. 1998. "Auctions versus Posted Price Selling: The Case of Correlated Private Valuations." Canadian Journal of Economics, 31(2): 395-410.

[68] Wasserstein, Bruce. 2001. Big Deal: Mergers and Acquisitions in the Digital Age. New York, NY: Warner Business. 


\section{Appendix A. Examples of the Equilibrium of the Sequential Mechanism}

Let bidders' values be drawn from the uniform distribution $F(v)=v$ for $v \in[0,1]$. Then $S(v)=\frac{1}{6}(1-v)^{2}$ (using note 13's formula), and so $(1) \Longrightarrow V_{S}=1-\sqrt{6 c} .{ }^{50}$ That is, a potential entrant would be just indifferent to entering against an incumbent with a value in the range $[1-\sqrt{6 c}, 1]$ (the probability of defeating such an incumbent will be $\frac{1}{2} \sqrt{6 c}$, and the expected profit conditional on doing so will be $\frac{1}{3} \sqrt{6 c}$, so the net benefit from entering would be $\left.\frac{1}{2} \sqrt{6 c} \cdot \frac{1}{3} \sqrt{6 c}-c=0\right)$.

Let $c=.06$, so $V_{S}=.4$. So - starting from any point of the game, and independent of past history or future $\left\{\rho_{j}\right\}-$ a bidder must signal that it has a value of at least .4 to deter further entry. It can do this by making a bid that, if its value were .4, would give it the same surplus if it successfully deterred entry as if it did not jump bid and accommodated further entry.

\section{3-bidder Example}

If there are exactly 3 bidders ( $\rho_{j}=1$ for $j \leq 3$, and zero otherwise), a first bidder with the deterring value of .4 who chose not to deter would win with probability $(.4)^{2}$, and earn $\frac{1}{3}(.4)$ conditional on winning, yielding an expected profit of .0213 . So if the first bidder's value is .4 or more it will jump bid to $.4-.0213=.3787$ and there will be no further entry.

If the first bidder's value is less than .4 , it will bid $\underline{v}=0$, the second bidder will then enter, and the two bidders will raise the price continuously until the lower of their two actual values is reached. Call this price $p$. If it was the second entrant that quit, the third bidder then enters (it remains unprofitable for the first bidder to deter) and if the third bidder's value exceeds $p$, the price continues to rise until the lower of the two remaining bidders' values is reached.

If, instead, it was the incumbent bidder (that is, the first entrant) that quit at $p$, the new incumbent has the opportunity to jump bid to deter the final potential entrant. If the new incumbent had the minimum deterring value, .4, but did not jump bid, its expected profit from competing with the third bidder would be $p(.4-p)$ (from the case in which the third value is below $p$ ) plus $\frac{1}{2}(.4-p)^{2}$ (from the case in which the third value is between $p$ and .4) equals $.08-p^{2} / 2$. So if the second bidder's value exceeds .4 , it makes a jump bid from $p$ to $.32+p^{2} / 2(>p)$ immediately after defeating the first bidder at the price $p$, and there is then no further entry. If its value is below .4 it does not jump bid, the third bidder then enters and, as before, if the third bidder's value exceeds $p$ the price then rises again until the lower of the two remaining bidders' values is reached.

To compute expected revenue, it is easiest to use $M R$ analysis: ${ }^{51}$ with probability $.4^{3}$ all

\footnotetext{
${ }^{50}$ If $c>1 / 6$, only one bidder enters either the sequential mechanism or the auction.

${ }^{51}$ To compute expected revenue directly, note that with probability .6 the first bidder deters at price .3787 .
} 
three bidders have values between 0 and .4 and so $M R$ s uniformly distributed between -1 and -.2 (since "demand" is linear when values are uniformly distributed). In this case, the winner will be the highest-value bidder, and have the highest of these three $M R$ s which is, on average, -.4 . With the remaining probability at least one bidder will have a value above .4 , and the first of these bidders in the queue will win yielding an expected $M R$ of .4 (using Fact 2). So total expected revenue equals $\left(.4^{3}\right)(-.4)+\left(1-.4^{3}\right)(.4)=.3488$. (It is easy to check that the auction's expected revenue equals .5).

\section{Alternative Timing of Jump Bidding}

As noted in Remark 4, each bidder's expected surplus would be unaffected by the timing of entrants' jump-bidding. If, for example, the first bidder bid 0, a second bidder with the minimum deterring value of .4 would expect surplus $.4(.4 / 3)$ by not deterring (it would have the highest signal with probability .4 , and would then face two bidders with values uniformly distributed below .4). So if the second bidder jumps immediately to $.4-.4(.4 / 3)=.3467$, it will scare off both the incumbent (the first bidder) and the subsequent potential entrant and obtain the same surplus. (An alternative assumption is that the incumbent would not, in equilibrium, immediately be scared off if its value exceeds the jump bid. In this case, the second bidder jumps to a price of .3425 and is then bid up (to an average of .3713) when the first bidder's value exceeds .3425, and the third bidder again does not enter.) Expected revenues are, of course, unaffected.

\section{Constant- $\rho$ Example}

If instead $\rho_{j}=\rho \leq 1 \forall j \geq 2$, a new entrant with the deterring value of $v^{*}$ who defeated an existing incumbent at price $p$ but chose not to deter would win if no higher-value bidder entered, and would then pay the maximum of $p$ and the highest among subsequent entrants' values. The probability that no subsequent entrant's value would exceed any amount $x \leq v^{*}$ is $(1-\rho)\left[1+\rho x+\rho^{2} x^{2} \ldots\right]=\left(\frac{1-\rho}{1-\rho x}\right)$, so the probability density of the highest among subsequent entrants' values equalling $x$ would be $\frac{\partial}{\partial x}\left(\frac{1-\rho}{1-\rho x}\right)=\frac{\rho(1-\rho)}{(1-\rho x)^{2}}$ for $p \leq x \leq v^{*}$, and this entrant's expected surplus would therefore be $\left[\left(v^{*}-p\right)\left(\frac{1-\rho}{1-\rho p}\right)+\int_{x=p}^{v^{*}}\left(v^{*}-x\right) \frac{\rho(1-\rho)}{(1-\rho x)^{2}} d x\right]=$ $\frac{1-\rho}{\rho} \ln \left(\frac{1-\rho p}{1-\rho v^{*}}\right)$. So the deterring bid of any entrant whose value is $v^{*}$ or more, and who de-

With probability $.6(.4)=.24$ the second bidder will deter the third bidder after beating the first bidder at price $p$ uniformly distributed between 0 and .4 and the deterring price is $.32+p^{2} / 2$, so the average price in this case equals $\int_{p=0}^{.4}\left(.32+p^{2} / 2\right) d p=.3467$. With probability $.6(.4)^{2}=.096$ neither of the first two bidders will deter and the third bidder's value is at least .4, so it will win at a price equal to the higher of the first two bidders' values, which is on average $(2 / 3) .4=.2667$. Finally, with probability $(.4)^{3}=.064$ all three bidders have values below .4 and the expected price will be the expected second-highest of these three values, that is, $(1 / 2) .4=.2$. So total expected revenue equals .6(.3787) $+.24(.3467)+.096(.2667)+.064(.2)=.3488$. 
feats the existing incumbent at price $p(p=\underline{v}=0$ for the first entrant $)$ is $v^{*}-\frac{1-\rho}{\rho} \ln \left(\frac{1-\rho p}{1-\rho v^{*}}\right)$.

To calculate expected revenue, we find the expected $M R$ of the winning bidder, as for the 3-bidder example above. ${ }^{52}$ The probability that there exists no bidder with a value above any $x \leq v^{*}$ is $1-\frac{1-x}{1-\rho x}$. So with probability $\frac{1-v^{*}}{1-\rho v^{*}}$ there will be a bidder with a value of at least $v^{*}$, and so an expected $M R$ of $v^{*}$. With probability density $\frac{\partial}{\partial x}\left(1-\frac{1-x}{1-\rho x}\right)=\frac{1-\rho}{(1-\rho x)^{2}}$ the winner's value is $x<v^{*}$, and $M R(x)=2 x-1$, so the expected revenue from the mechanism is $v^{*} \frac{1-v^{*}}{1-\rho v^{*}}+\int_{x=0}^{v^{*}}(2 x-1) \frac{1-\rho}{(1-\rho x)^{2}} d x=\frac{v^{*}}{\rho}\left[1+\frac{(1-\rho)^{2}}{\left(1-\rho v^{*}\right)}\right]+\frac{2(1-\rho)}{\rho^{2}} \ln \left(1-\rho v^{*}\right)$.

In the perfect sequential equilibrium, $v^{*}=V_{S}=1-\sqrt{6 c}$ and, for $c=.06, v^{*}=V_{S}=.4$ (as in the 3-bidder example above). If, for example, $\rho=.8$ the expected revenue $\approx .29$. (It is not hard to check the auction's expected revenue $\approx .37$.)

\section{Appendix B. Proofs of Lemmas}

Proof of Lemma 2: It is straightforward from the discussion in the text that it is a perfect Nash equilibrium for any entrant, immediately after entry, to jump bid to the price that deters any future entry, if and only if it has a value $\geq v^{*}$, for some $v^{*} \geq V_{S}$. Furthermore, there cannot be a constant deterring "cut-off" value $>V_{K}$, because if two bidders had values $>V_{K}$ but $<v^{*}$ then a further new entrant would not be deterred and would face a minimum price $>V_{K}$. But its expected profits would be less than the profits from facing a fixed price of $V_{K}$, which from (2) are zero, which is a contradiction. ${ }^{53}$ So $v^{*} \in\left[V_{S}, V_{K}\right]$.

Now consider any sequential equilibrium in which, at some stage, some bidders with values $\geq V_{S}$ do not deter; and at that stage let $\widetilde{p}$ be the bid which type $V_{S}$ would be just indifferent about jumping to if such a jump bid did deter future entry. Then at this stage of such an equilibrium (i) all types with values $\geq V_{S}$ would deviate from their equilibrium strategy to bidding $\widetilde{p}$ if doing so did deter (since types that were anyway deterring would thereby deter at a lower price, and other types above $V_{S}$ gain more than type $V_{S}$ gains by deterring and therefore strictly gain) and (ii) no other type would deviate from its equilibrium strategy to bidding $\widetilde{p}$ even if doing so did successfully deter all further entry. So a type of bidder with value $\geq V_{S}$ failing to deter cannot, at any stage, be part of a perfect sequential equilibrium. The unique perfect sequential equilibrium therefore has $v^{*}=V_{S}{ }^{54}$

\footnotetext{
${ }^{52}$ As before, it is possible, but more cumbersome, to compute expected revenue directly - see note 51.

${ }^{53}$ Technically, this argument requires a positive probability of at least three potential entrants existing. However, any equilibrium in which the "cut-off value" is above $V_{K}$ in any period not only fails the "intuitive criterion", but is not even robust to the "test of dominated messages" (see In-Koo Cho and David Kreps (1987), and Kreps, 1990, p.436): making the deterring bid corresponding to a "cut-off value" of $V_{K}$ is strictly dominated for all types with values below $V_{K}$ (however any potential entrant would respond, all these types would do better not to jump bid), so making this bid must be interpreted as signalling a value $\geq V_{K}$, and will therefore prevent further entry.

${ }^{54}$ Strictly, if $\rho_{j}=1 \forall j$ this argument proves only that this is the unique neologism-proof equilibrium. It does not quite prove it is the unique perfect-sequential equilibrium, because a bidder with value below $V_{S}$ is
} 
Proof of Lemma 3: In both mechanisms, the direct private and social cost of entering is the same, that is, $c$.

In the auction the private and social contribution of each bidder is the same, namely zero for everyone other than the winner and the difference between the top two values for the winner. Since the expected contribution is therefore clearly also decreasing in the number of entrants, the correct number enter.

In the sequential mechanism, if no bidder with a value of $v^{*}$ or more has yet entered, the social contribution from one more entry is at least $T\left(v^{*}\right) \geq c$ so entry is socially efficient. Also, since the entrant will be able to deter entry through a bid no greater than $v^{*}$, it is also profitable to enter, even ignoring potential profits from winning with a bid, or even a value, below $v^{*}$. If a bidder with a value of $v^{*}$ or more has already entered, it is inefficient and unprofitable for a new bidder to enter even ignoring the possibility of others entering later: the expected private and social contributions from entry would be $S\left(v^{*}\right) \leq c$ (from Lemma $2, S\left(V_{S}\right)=c$ and $\left.v^{*} \geq V_{S}\right)$, so the private and social choices are again identical.

Proof of Lemma 4: $:^{55}$ From Remark 4, neither sales process's expected revenue would be affected if the actual number of potential entrants, $k$, were revealed to everyone prior to any entry decisions. So consider this case.

We first demonstrate that with $2 \leq k \leq n^{*}$, the auction is always strictly more profitable in expectation: ${ }^{56}$ if no bidders' value exceeds $v^{*}$, the two sales processes yield the same price. If instead at least one potential bidder prior to the last bidder had a value exceeding $v^{*}$, consider the first such bidder. The deterring price it sets is such that if its value were $v^{*}$ it would be indifferent between deterring at this price, and not deterring. But a bidder with value $v^{*}$ is also indifferent between not deterring, and buying for sure at a price equal to the minimum of $v^{*}$ and the highest among all other past and potential future bidders' values. So the deterring price equals the expectation of the minimum of $v^{*}$ and the highest among all other potential bidders' values. But the auction would achieve the second highest among all bidders' values, which is obviously strictly higher in expectation.

With $k>n^{*}$, reducing the number of bidders by 1 leaves the auction unaffected (since only $n^{*}$ bidders enter anyway). But reducing the number of bidders by 1 strictly lowers

weakly willing to bid $V_{S}$ if $\rho_{j}=1 \forall j$, which spoils the exact Grossman-Perry argument (but not Farrell's). However, if bidders prefer no bid to a surely-losing one (e.g., there are small bidding costs) or of course if $\rho_{j}$ $<1$ for any $j$, all equilibria other than the constant-cutoff equilibrium with $v^{*}=V_{S}$ fail Grossman-Perry's exact refinement, as well as Farrell's.

${ }^{55}$ The working paper version of this paper gives a shorter proof using " $M R$ analysis" following the intuition given in the main text.

${ }^{56}$ Note this would be immediate in Myerson (1981)'s "regular case" - which corresponds to assuming downward sloping $M R$ s - because the auction is then the optimal method of sale to a set of potential bidders who will all enter. 
the sequential mechanism's profitability: if any of the first $k-2$ would deter they would now do so at a lower price than if a total of $k$ bidders were expected since the deterring price equals the expectation of the minimum of $v^{*}$ and the highest among all other potential bidders' values (as shown in the previous paragraph); clearly, if none of the first $k-2$ would deter, the price is also strictly lowered in expectation. So for $k>n^{*}$, the profitability of the auction minus the profitability of the sequential mechanism is strictly decreasing in $k$.

Now lowering $\rho_{j}$ reduces the probability of exactly $k$ potential bidders for all $k \geq j$ by an equal proportion, and increases the probability of $k=j-1$. If $j>n^{*}$, it is immediate from the preceding paragraph that transferring probability from $k \geq j$ to $k=j-1$ strictly increases the relative profitability of the auction. If $3 \leq j \leq n^{*}$, since (by the argument for $2 \leq k \leq n^{*}$ ) the auction is strictly more profitable for all the cases $2 \leq k \leq j-1$, it follows that if the auction is at least as profitable for the sequence $\left\{\rho_{j}\right\}_{j=1}^{\infty}$ as a whole, then a proportional reduction in the "weight" on all the cases $k \geq j$ must leave the auction strictly more profitable for the sequence as a whole. Finally, lowering $\rho_{2}$ simply increases the relative probability of $k=1$, where both mechanisms trivially earn the same revenue, $\underline{v}$.

In sum, therefore, if the auction is at least as profitable as the sequential mechanism for a sequence $\left\{\rho_{j}\right\}_{j=1}^{\infty}$, then lowering any $\rho_{j}$ leaves the auction at least as profitable for $j=2$, and strictly more profitable for all $j>2$.

Proof of Lemma 5: The winner of the sequential mechanism is the first bidder with a value exceeding $v^{*}$. So for $v>v^{*}$ the ratio of the density of the auction-winner's value to that of the sequential-mechanism-winner's value is $\left[n F(\cdot)^{n-1} f(\cdot)\right] /\left[\frac{f(\cdot)}{1-F\left(v^{*}\right)}\right]$, which is increasing. So the former density is first higher (for $v<v^{*}$ ), then lower (it obviously cannot always be higher), and finally higher again (it cannot stay lower since the distributions have the same mean), than the latter density, which implies second-order stochastic dominance.

Proof of Lemma 6: Recall $S(v)$ is the expected surplus of a bidder who competes in an ascending auction against a second bidder, when their values are drawn independently from $F(\cdot)$, conditional on the second bidder's value exceeding $v$; and $T(v)$ is the expected surplus of the first bidder if the second bidder's value equals $v$.

Clearly $S(v)$ is decreasing in $v$, so it is convex in $v$ if, $\forall$ constants $a, b$, with $b<0$, whenever the expression $S(v)-(a+b v)$ changes sign twice, it is first positive, then negative, then positive again.

Furthermore, since $S(v)=E\{T(w) \mid w \geq v\}$, and $v=E\{M R(w) \mid w \geq v\}$ (this is Fact 2) and, of course, $a=E\{a \mid w \geq v\}$, we have

$$
S(v)-(a+b v)=E\{[T(w)-a-b M R(w)] \mid w \geq v\}
$$


in which $I_{[w \geq v]}$ is the indicator function.

$$
=\int_{w=\underline{v}}^{\bar{v}}[T(w)-a-b M R(w)]\left[\frac{f(w)}{1-F(v)} I_{[w \geq v]}\right] d w,
$$

We know from standard consumer theory that $T(v)$ is convex and decreasing in $v$, so it is straightforward that if $M R(v)$ is convex in $v$, then whenever, with $b<0$, the expression $[T(w)-a-b M R(w)]$ changes sign twice, it is first positive, then negative, then positive again. But it follows from Karlin (1968) that since $\left[\frac{f(w)}{1-F(v)} I_{[w \geq v]}\right]$ is known to be Totally Positive of order 3 , the sign pattern is carried over ${ }^{57}$ to $\int_{w=\underline{v}}^{\bar{v}}[T(w)-a-b M R(w)] K(v, w) d w$, as required.

Proof of Lemma \%: Part (i): for $\rho_{j}=1 \forall j$, assume for contradiction that the sequential mechanism has as many bidders as the auction in expectation. Then the distribution of highest values in the sequential mechanism must first-order stochastically dominate the distribution in the auction, since entrants into the sequential mechanism win if and only if their values are $v^{*}$ or more, while auction participants sometimes lose with values above $v^{*}$ and sometimes win with values below $v^{*}$. So since an additional bidder's expected profits from entering the sequential mechanism are zero when $v^{*}=V_{S}$, its expected profits from entering the auction are positive, which is a contradiction. So the auction attracts more bidders in expectation.

Now, $\forall\left\{\rho_{j}\right\}_{j=1}^{\infty}$, the auction has a higher probability of a $k$ th bidder entering, for $2 \leq$ $k \leq n^{*}$ (since a $k$ th potential bidder would always participate in the auction and not always participate in the sequential mechanism, for $2 \leq k \leq n^{*}$ ) and the sequential mechanism obviously has a higher probability of a $k$ th bidder entering, for any $k>n^{*}$. So since the auction has more expected bidders for $\rho_{j}=1 \forall j$, it also has more expected bidders if we reduce (by lowering $\rho_{m}$ ) the probability of a $k$ th bidder for all $k \geq m$, for any $m$.

Part (ii) is straightforward.

Proof of Lemma 8: Recall that entry decisions and expected surplus for all buyers and the seller would be unaffected if the number of potential entrants, $k$, were revealed in advance of the first bidder's entrance (Remark 4). So consider the mechanisms with $k$ revealed in advance. Observe that conditional on actually entering a potential entrant's expected surplus from the sequential mechanism is independent of its position in the queue (if its value is less than $v^{*}$ it wins whenever its value exceeds all other $k-1$ signals; otherwise it wins with probability 1 , and must pay the same that it would expect to pay if its value were $V s$ and it did not deter). Its expected share of surplus from the sequential mechanism therefore equals the expected fraction of actual entrants that it represents, just as in the auction. So

\footnotetext{
${ }^{57}$ This is the variation diminishing property of totally positive kernels developed in Karlin (1968). Jewitt (1987) gives a concise summary of the theory, and application to economics. We are very grateful to Ian Jewitt for helping us with this proof.
} 
because the first bidder always enters, and (by Lemma 7) there are fewer expected entrants in the sequential mechanism than in the auction, the first bidder expects a larger share of the buyers' surplus in the sequential mechanism than in the auction. 




Figure 1:

Densities of winner's value for an Auction and Sequential Mechanism with identical expected winning bid and identical expected winner's value.

[Drawn for bidders' values uniformly distributed on $[0,1]$;

for the Auction, $n^{*}=3$, so expected winning bid $=\cdot 5$;

for the Sequential Mechanism we assume the same cutoff (winning) bid, $\cdot 5$, so with an infinite number of potential entrants, the expected winner's value $=\cdot 75$, in both cases.] 